\title{
Grassland gross carbon dioxide uptake based on an improved model tree ensemble approach considering human interventions: global estimation and covariation with climate
}

\author{
WEI LIANG ${ }^{1,2,3,4}$, YIHE LÜ ${ }^{2}$, WEIBIN ZHANG ${ }^{1,3,4}$, SHUAI LI ${ }^{1}$, ZHAO JIN ${ }^{1,3,4}$, \\ PHILIPPE CIAIS ${ }^{5}$, BOJIE FU ${ }^{2}$, SHUAI WANG ${ }^{2}$, JIANWU YAN ${ }^{1,3,4}$, JUNYI LI ${ }^{1,3}$ and HUIMIN SU ${ }^{1}$ \\ ${ }^{1}$ College of Tourism and Environment, Shaanxi Normal University, Xi'an 710119, China, ${ }^{2}$ State Key Laboratory of Urban and \\ Regional Ecology, Research Center for Eco-Environmental Sciences, Chinese Academy of Sciences, Beijing 100085, China, \\ ${ }^{3}$ Shaanxi Key Laboratory of Tourism Informatics, Xi' an 710119, China, ${ }^{4}$ Research Center for Geographical Environment Change \\ and Sustainable Development, Shaanxi Normal University, Xi'an 710119, China, ${ }^{5}$ LSCE, UMR CEA-CNRS, Bat. 709, CE, \\ L'Orme des Merisiers, F-91191 Gif-sur-Yvette, France
}

\begin{abstract}
Grassland ecosystems act as a crucial role in the global carbon cycle and provide vital ecosystem services for many species. However, these low-productivity and water-limited ecosystems are sensitive and vulnerable to climate perturbations and human intervention, the latter of which is often not considered due to lack of spatial information regarding the grassland management. Here by the application of a model tree ensemble (MTE-GRASS) trained on local eddy covariance data and using as predictors gridded climate and management intensity field (grazing and cutting), we first provide an estimate of global grassland gross primary production (GPP). GPP from our study compares well (modeling efficiency NSE = 0.85 spatial; NSE between 0.69 and 0.94 interannual) with that from flux measurement. Global grassland GPP was on average $11 \pm 0.31 \mathrm{Pg} \mathrm{C} \mathrm{yr}^{-1}$ and exhibited significantly increasing trend at both annual and seasonal scales, with an annual increase of $0.023 \mathrm{Pg} \mathrm{C}(0.2 \%)$ from 1982 to 2011. Meanwhile, we found that at both annual and seasonal scale, the trend (except for northern summer) and interannual variability of the GPP are primarily driven by arid/semiarid ecosystems, the latter of which is due to the larger variation in precipitation. Grasslands in arid/semiarid regions have a stronger (33 $\left.\mathrm{g} \mathrm{C} \mathrm{m}^{-2} \mathrm{yr}^{-1} / 100 \mathrm{~mm}\right)$ and faster (0- to 1-month time lag) response to precipitation than those in other regions. Although globally spatial gradients (71\%) and interannual changes $(51 \%)$ in GPP were mainly driven by precipitation, where most regions with arid/semiarid climate zone, temperature and radiation together shared half of GPP variability, which is mainly distributed in the high-latitude or cold regions. Our findings and the results of other studies suggest the overwhelming importance of arid/semiarid regions as a control on grassland ecosystems carbon cycle. Similarly, under the projected future climate change, grassland ecosystems in these regions will be potentially greatly influenced.
\end{abstract}

Keywords: arid/semiarid ecosystems, climate control, data-driven method, global grassland GPP, grazing and cutting, model tree ensembles, spatiotemporal patterns

Received 17 April 2016; revised version received 24 November 2016 and accepted 3 December 2016

\section{Introduction}

Carbon cycle in terrestrial ecosystems has been attracted considerable attention by scientists in recent years (Nemani et al., 2003; Piao et al., 2008; Zhao \& Running, 2010; Ahlström et al., 2015; Liang et al., 2015; Wolf et al., 2016; Yang et al., 2016b), given that the land is currently absorbing about one-third of carbon dioxide $\left(\mathrm{CO}_{2}\right)$ emissions from fossil fuel burning (during the period 2000-2008) (Le Quere et al., 2009). As the largest global carbon flux (Battin et al., 2009; Beer et al., 2010), gross primary production (GPP) drives several

Correspondence: Yihe Lü, tel./fax +86 10 62923559, e-mail: lyh@ rcees.ac.cn ecosystem functions, such as respiration and vegetation growth. GPP is the basis for food, fiber, and wood production; thus, it can be in favor of human welfare (Beer et al., 2010). Consequently, understanding the spatiotemporal patterns of GPP and how environmental factors drive its variability are crucial to account for their present status and predict their future status.

Most previous studies on ecosystem carbon fluxes have focused on forests (Gök et al., 2000; Goulden et al., 2010; Christian et al., 2015; Yang et al., 2016b), because of their potential to sequester large amounts of carbon. However, as one of the most widespread vegetation types worldwide (covers approximately 20-40\% of the world's land surface) (Scurlock \& Hall, 1998; Suttie 
et al., 2005), grasslands provide vital ecosystem services such as carbon storage, forage production, and habitat critical for many species (Piao et al., 2007; Chou et al., 2008; Chang et al., 2013; Fry et al., 2013; Fu et al., 2014; Mowll et al., 2015). More than 180 million people depend on livestock supported by grasslands for their livelihoods in the developing world (Kruska et al., 2003). More importantly, these low-productivity and water-limited ecosystems are generally assumed to be mostly sensitive and vulnerable to climate perturbations and human intervention (e.g., livestock grazing and cutting) (Knapp \& Smith, 2001; Novick et al., 2004; Ponce-Campos et al., 2013; Yang et al., 2016a), which in turn will feed back on atmospheric $\mathrm{CO}_{2}$ concentrations (IPCC, 2007, 2013). Meanwhile, the uncertainty with regard to the role of grasslands in the carbon cycle is largely associated with their sensitivity and response rate to climate change (Chou et al., 2008; Marcolla et al., 2011), which is normally depended on the geographical locations. Accordingly, in the context of global climate change projected in the future (IPCC, 2013; Donat et al., 2016), a systemic analysis of the grassland GPP patterns in different zones and its climate controls is critical not only for terrestrial carbon cycle, but also for grassland resources sustainability (Piao et al., 2007; Wu et al., 2009; Guo et al., 2015).

A range of carbon flux studies have begun to concentrate on grassland biome at regional and continental scales (Novick et al., 2004; Marcolla et al., 2011; Zhang et al., 2016). Nevertheless, these researches historically focused on net ecosystem exchange of carbon (NEE). Until recently, few studies have reported in quantifying grassland ecosystems GPP. For example, based on $\mathrm{CO}_{2}$ flux measurements from 20 European grassland sites, Gilmanov et al. (2007) found that European grassland GPP ranges from $1700 \mathrm{~g} \mathrm{CO}_{2} \mathrm{~m}^{-2} \mathrm{yr}^{-1}$ in dry seminatural pastures to $6900 \mathrm{~g} \mathrm{CO}_{2} \mathrm{~m}^{-2} \mathrm{yr}^{-1}$ in intensively managed Atlantic grasslands. Li et al. (2007) estimated the seasonal dynamics of GPP of the three alpine grasslands in the Tibetan Plateau using the moderate resolution imaging spectroradiometer (MODIS) images and climate data. At global scale, a recent modeling study estimated an annual sum of $\sim 40$ Pg C GPP from tropical savannas and grasslands, and temperate grasslands and shrublands, accounting for $32.7 \%$ of the global terrestrial GPP (Beer et al., 2010). However, to our knowledge, the total amount of global grassland GPP remains uncertain, and its pattern and variability has not been comprehensively and systematically characterized based on observations owing to the lack of adequate methods.

It is impossible to monitor directly GPP at large spatial scales. Alternatively, two main spatially explicit approaches have been used. The first one is to apply process-driven land surface models. These models are complex and bear uncertainty from model structure and parameter values. Parameters related to plant traits are most often given fixed values per plant functional type. In the case of grasslands, where species composition changes fast in response to environmental drivers on subseasonal to multiannual scales, a parametric and rigid description of phenology and photosynthetic traits is a limitation of the ability of process models to simulate GPP distribution. This was proved by Macbean et al. (2015) who found that calibrated parameters in a dynamic ecosystems model (i.e., ORCHIDEE) have predictive value for forests, but poor performances for grasslands, in particular C4 grasslands. A complementary approach is to use data-driven models, such as remote sensing-based models. The MODIS GPP, which applies the maximum light-use efficiency (LUE) (Monteith, 1972; Monteith \& Moss, 1977), provides a quantitative and dynamic measurement of vegetation productivity (Running et al., 2004). This algorithm is straightforward and simple, but exists many uncertainties, because it assumes that LUE is constant or it is modeled from ancillary meteorological variables (Goetz \& Prince, 1999; Yang et al., 2013, 2014a,b). Another data-driven model is machine learning approach. The advantage of this method is that the results depend less on theoretical assumptions (Beer et al., 2010), but it should be kept in mind that nothing replaces real measurements and that the extrapolation of data-driven models far from their range of calibration can also cause biases in their results.

Among machine learning interpolation algorithms, model tree ensemble (MTE) pioneered by Jung et al. (2009) was used to scale up $\mathrm{CO}_{2}$ and energy fluxes over the entire globe when the global network of eddy covariance sites (www.fluxdata.org) reached in the late 2000s a sufficient density to cover the climate space of a large range of biomes. MTE products derived from eddy covariance networks were the first of that kind for GPP (Beer et al., 2010), and delivered new insights on evapotranspiration trends (Jung et al., 2009, 2011; Zeng et al., 2014), so that they found users in a large community of carbon cycle and land surface modelers for model benchmarking, and are also used to explore the drivers of energy and $\mathrm{CO}_{2}$ fluxes (Yang et al., 2015; Murray-Tortarolo et al., 2016). To our knowledge, datadriven models extrapolating GPP and energy fluxes based on eddy covariance networks do not differentiate between ecosystem types, and rather scale fluxes using the same geostatistical relations between flux and predictors across ecosystems and biomes. Further, it is a fact that management intensity strongly affects ecosystem fluxes (Soussana et al., 2007; Chang et al., 2016), while in current MTE models this driver is merely (implicitly) included through the use of satellite greenness 
data as predictors. As grassland GPP depends primarily on management (Wohlfahrt et al., 2008; Chang et al., 2013), and the intensity of management varies strongly between regions, application of MTE to this biome is expected to benefit from gridded management information, which was only established recently by Chang Jinfeng (personal communication) from Herrero et al. (2013).

The objectives of this study were to (1) evaluate the performance of the model tree ensemble (MTE) that takes into account the grassland management (hereafter MTE-GRASS) in estimating the global grassland GPP; (2) characterize the mean annual and seasonal GPP of grassland ecosystem; (3) investigate the changes (including trend and interannual variability (IAV)) in grassland GPP at both annual and seasonal scales from 1982 to 2011; and (4) explore the relationship between GPP and climate variables (i.e., precipitation, temperature, and short-wave radiation (SWrad)) across global grassland ecosystems.

\section{Materials and methods}

\section{MTE-GRASS model}

In order to estimate monthly gridded global grassland GPP, the model tree ensemble (MTE) approach, which is a machine learning algorithm, was applied. Model trees were developed from, but has proven superior to, classification and regression tree (Wang \& Witten, 1997; Vens \& Blockeel, 2006; Jung et al., 2009), given that target variable (GPP in this study) is predicted by a set of multiple linear regressions from explanatory variables. Each regression model is only valid within certain conditions defined by a model tree. In general, two steps are required to produce global GPP from flux tower local measurements: (1) The MTE is trained against eddy covariance GPP estimates at site level using satellite-derived fraction of absorbed photosynthetically active radiation $\left(f_{\text {PAR }}\right)$ and meteorological data as explanatory variables and (2) using gridded information about all these explanatory variables in combination to the trained MTE GPP to predict global GPP pattern. A flowchart of the modeling global grassland GPP is shown in Fig. 1, and details are described in the following sections.

\section{Data processing}

First, the observed GPPs with different time resolutions (30 $\mathrm{min}, 1 \mathrm{~h}$, and weekly) from eddy covariance flux tower (www.fluxdata.org), which vegetation type is grass according to International Geosphere-Biosphere Program definition (IGBP GRA), were aggregated to monthly values. Then, they were used to parameterize the models together with the drivers either obtained at the site (precipitation and temperature) or extracted at the flux tower location (gridded data). In total, 30 explanatory variables of five general types from 45 stations (1416 site-months) were used to train MTE (Table 1). These data were randomly divided into five groups (four for training and one for test). Here, we evaluated the performance of MTE based on fivefold cross-validation. The observed GPP for each of these five groups was predicted based on the training using the remaining four groups.

\section{MTE-GRASS construction}

The MTE for grassland (MTE-GRASS) construction can be generally divided into two steps, that is, the initial model tree establishment and trees pruning and random growth. The initial large tree is grown based on recursive partitioning. The critical step of model tree training is to identify which leaf node is split and the best split for a given node. For the former, all nodes attempted to split, and calculated the Bayesian Information Criterion (BIC) value of all possible new trees and old one (before split). Then, which leaf node is split for each time is determined by the largest decrease in BIC value between old tree and new tree. For the latter (split location), each split variable (30 variables) tended to all possible splits, and we found the location where the sum of squared errors (SSE) of the model in the right and left child is minimal (min $\left.\mathrm{SSE}_{\text {left }}+\mathrm{SSE}_{\text {right }}\right)$ by multiple linear regressions. Variables selected for these regressions were based on the minimal BIC value from the tenfold cross-validation. The above procedure is repeated until $<40$ samples are left in the final leaf node or that the BIC value of old tree minus new tree is below 0.05 . The formula of the BIC and SSE could be found in supporting materials.

Once a tree evolved by the approach above, we further developed many trees using this tree. First, this tree was pruned at a randomly chosen interior node (child leaf node number $>2$ ), and random splits were occurred in this interior node. Then according to the minimal BIC and minimal SSE described above, the tree continued to growth until it stops again.

We stored these trained trees in a workspace, and each tree was randomly selected to be pruned. However, the selection probability was determined by the BIC value, with lower BIC value being more easily selected. Then, we repeated the trees pruning and random growth processes, and a large numbers of trees (1000 in this study) were evolved. The 1000 trees were sorted by BIC value in ascending order, and then we calculated the correlation coefficient $\left(R^{2}\right)$ between the observed GPP and the mean modeled GPP from selected trees until we see diminishing improvements. Finally, the best trees are selected for the model tree ensemble (24 trees).

\section{Global grassland GPP estimation}

The trained model trees were extended to a global grassland domain using gridded information on the explanatory variables during the period 1982-2011. The computations were only carried out for grassland ecosystems according to the definition of the Global Land Cover 2000 Project (GLC2000). Each estimated gridded grassland GPP was given as the mean value of the 24 best-independent trees. 


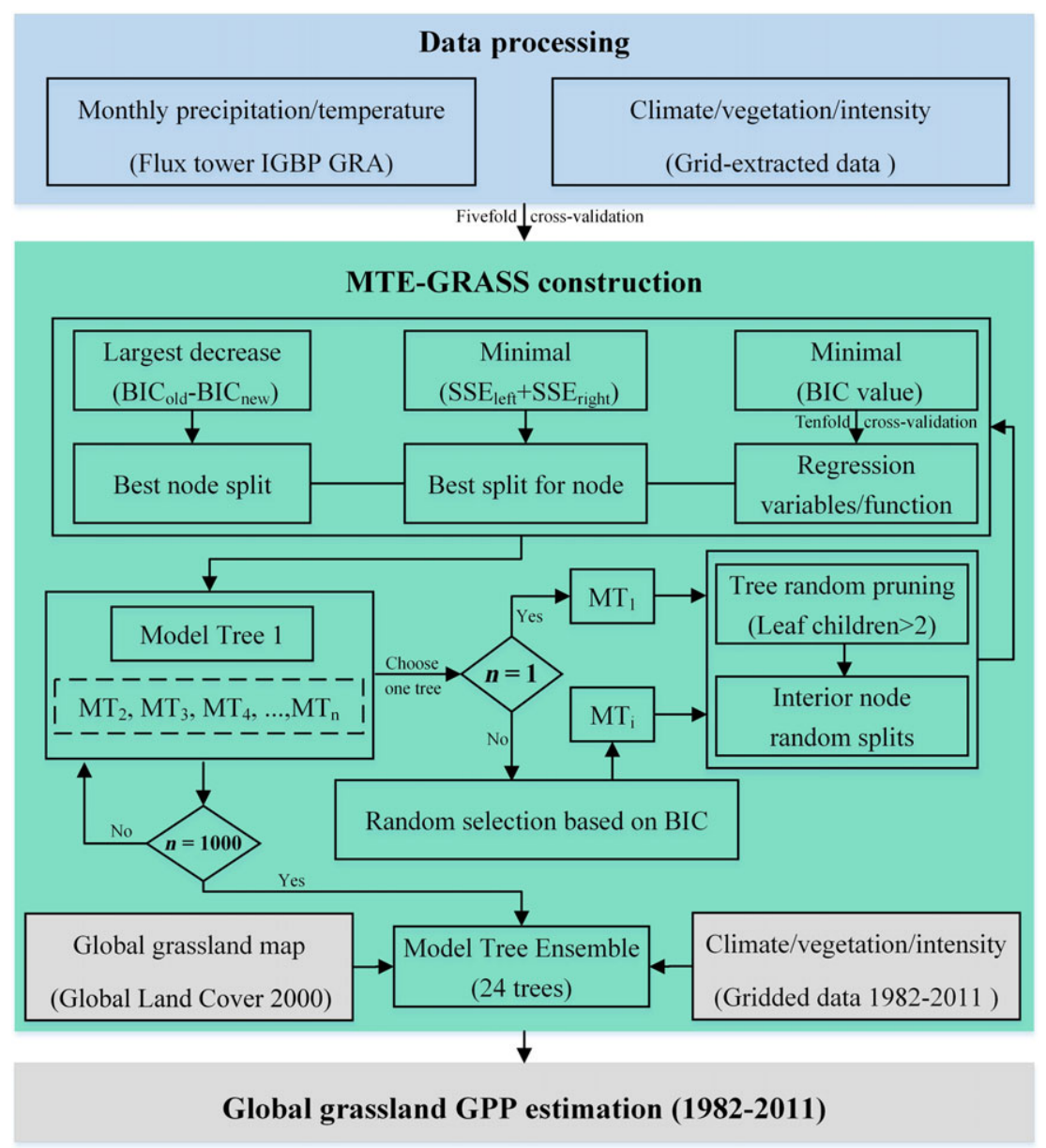

Fig. 1 Flowchart for estimating global grassland gross primary production (GPP) based on a model tree ensemble approach. [Colour figure can be viewed at wileyonlinelibrary.com].

\section{Partitioning of interannual variations}

To partition the contribution of individual climate zone to interannual variability (IAV) in global GPP, we applied a method proposed by Ahlström et al. (2015). For a given flux (GPP), the contribution of the IAV of a grid cell or climate zones $j$ to the global GPP IAV is defined as:

$$
f_{j}=\frac{\sum_{t} \frac{x_{j t}\left|X_{t}\right|}{X_{t}}}{\sum_{t}\left|X_{t}\right|}
$$

where $x_{j t}$ is the flux anomaly (departure from a long-term trend) for region $j$ at time $t$ (in years) and $X_{t}$ is the global flux anomaly, so that $X_{t}=\sum_{j} x_{j t}$. This method enables a comparison of their relative importance (contribution) in driving global GPP IAV. Regions with high scores drive the overall variations, while regions with low scores contribute less. More details about this method can be found in the supplementary materials from a recent work by Ahlström et al. (2015).

\section{Windowed cross-correlation}

As the impact of climate factors on GPP is expected to show some time lags due to the variability in temporal response of vegetation to climate variables (Chen et al., 2014; Yang et al., 2014a,b; Liang et al., 2015), a windowed cross-correlation (WCC) was applied between monthly GPP and precipitation anomalies to determine the time lag in the response (Boker et al., 2002). The common cross-correlation of two time series $(X, Y)$ at lag $\varsigma$ (month) is calculated as follows:

$$
\gamma(X, Y, \varsigma)=\frac{1}{N-\varsigma} \sum_{t=1}^{N-\varsigma} \frac{\left(X_{t}-\mu_{X}\right)\left(Y_{t}-\mu_{Y}\right)}{\sigma_{X} \sigma_{Y}},
$$

where $t$ indicates time in months, ranging from 1 to $N ; \mu_{\mathrm{X}}$ and $\mu_{Y}$ are the averages of $X$ and $Y ; \sigma_{X}$ and $\sigma_{Y}$ are the standard deviations of $X$ and $Y$, respectively.

\section{Grassland map and management data}

To depict the spatial pattern of GPP, it is essential to have a grasslands distribution map. Here, the grassland map with $1 / 12$ degree spatial resolution was derived from the 'grassland' class obtained from the Joint Research Center (JRC) of European Commission under the project of GLC2000 on board the SPOT 4 satellite, without consideration of temporal changes in grasslands distribution (Fig. 2). In the GLC2000, grasslands 
Table 1 List of explanatory variables used for training the model tree ensemble (MTE)*

\begin{tabular}{|c|c|c|c|}
\hline Variables & Type & Type of Variability & Source/Reference \\
\hline \multicolumn{4}{|l|}{ Climate (for data stratification) } \\
\hline Mean annual temperature & Split & Static & CRU \\
\hline Mean annual precipitation sum & Split & Static & CRU \\
\hline Mean annual climatic water balance & Split & Static & CRU \\
\hline Mean annual potential evapotranspiration & Split & Static & CRU \\
\hline Mean annual incoming radiation & Split & Static & CRU-NCEP \\
\hline Mean annual number of wet days & Split & Static & CRU \\
\hline Mean annual relative humidity & Split & Static & CRU \\
\hline Mean monthly temperature & Split & Monthly but static over years & CRU \\
\hline Mean monthly precipitation sum & Split & Monthly but static over years & CRU \\
\hline Mean monthly climatic water balance & Split & Monthly but static over years & CRU \\
\hline Mean monthly potential evapotranspiration & Split & Monthly but static over years & CRU \\
\hline Mean monthly incoming radiation & Split & Monthly but static over years & CRU-NCEP \\
\hline Mean monthly number of wet days & Split & Monthly but static over years & CRU \\
\hline Mean monthly relative humidity & Split & Monthly but static over years & CRU \\
\hline \multicolumn{4}{|l|}{ Vegetation structure } \\
\hline Maximum fraction of absorbed & Split & Years & Zhu et al., 2013; \\
\hline \multicolumn{4}{|l|}{ photosynthetic active radiation $\left(f_{\mathrm{PAR}}\right)$ of year } \\
\hline Minimum $f_{\text {PAR }}$ of year & Split & Years & Zhu et al. (2013) \\
\hline Max-Min $f_{\text {PAR }}$ of year & Split & Years & Zhu et al. (2013) \\
\hline Mean annual $f_{\text {PAR }}$ & Split & Years & Zhu et al. (2013) \\
\hline Sum of $f_{\mathrm{PAR}}$ over the growing season & Split & Years & Zhu et al. (2013) \\
\hline Mean $f_{\text {PAR }}$ of the growing season & Split & Years & Zhu et al. (2013) \\
\hline Growing season length derived from $f_{\mathrm{PAR}}$ & Split & Static & Zhu et al. (2013) \\
\hline \multicolumn{4}{|l|}{ Meteorology } \\
\hline Temperature & Split \& Regression & Monthly & Flux tower sites \\
\hline Precipitation & Split \& Regression & Monthly & Flux tower sites \\
\hline$f_{\mathrm{PAR}}$ & Split \& Regression & Monthly & Zhu et al. (2013) \\
\hline Short radiation & Split \& Regression & Monthly but static over years & CRU-NCEP \\
\hline \multicolumn{4}{|l|}{ Human activity } \\
\hline Grassland management intensity & Split & Years & Personal communication \\
\hline \multicolumn{4}{|l|}{ Vegetation status } \\
\hline$f_{\mathrm{PAR}} *$ Short radiation & Split \& Regression & Years & Zhu et al. (2013) \\
\hline Sum of $f_{\mathrm{PAR}} *$ Short radiation of year & Split & Years & Zhu et al. (2013) \\
\hline Maximum of $f_{\mathrm{PAR}} *$ Short radiation of year & Split & Years & Zhu et al. (2013) \\
\hline
\end{tabular}

*In 'Type' column, 'Split' denotes the variable used for data stratification and 'Split \& Regression' represents the variable used for data stratification and regression. In 'Type of variability' column, 'Monthly' variables are continuously updated for each month; 'Static' variables remain constant across all months and years; 'Monthly but static over years' variables change monthly, but the monthly values are repeatedly used across all years; and 'Yearly' variables have the same value within a year, but this value is updated for each year.

are defined as herbaceous cover, closed-open and sparse herbaceous or sparse shrub cover, which are aggregated from regional classes using Food and Agriculture Organization of the United Nations (FAO) Land Cover Classification System (LCCS). The total area of grasslands is $2.71 \times 10^{7} \mathrm{~km}^{2}$, which mainly includes rangelands, steppes, and Arctic tundra.

Global grids of annual grassland management intensity dataset $\left(0.5^{\circ} \times 0.5^{\circ}\right)$ used for training were from Chang Jinfeng (personal communication) (Fig. S1). This dataset includes the proportions of extensively as well as of intensively managed grasslands (grazing and cutting) from 1982 to 2011, constrained by the total forage requirement of grass-fed livestock numbers. More details about this dataset, including the calculation of the forage requirement and the fraction of animals that receive complementary crop feed products, can be found in Chang et al. (2015a). The management intensity data at each flux tower site used for training are not available; alternatively, we extracted these data at each grid where these sites are located.

\section{Meteorological data}

Meteorological data (including precipitation, temperature, SWrad and wet day frequency, and relative humidity) and 


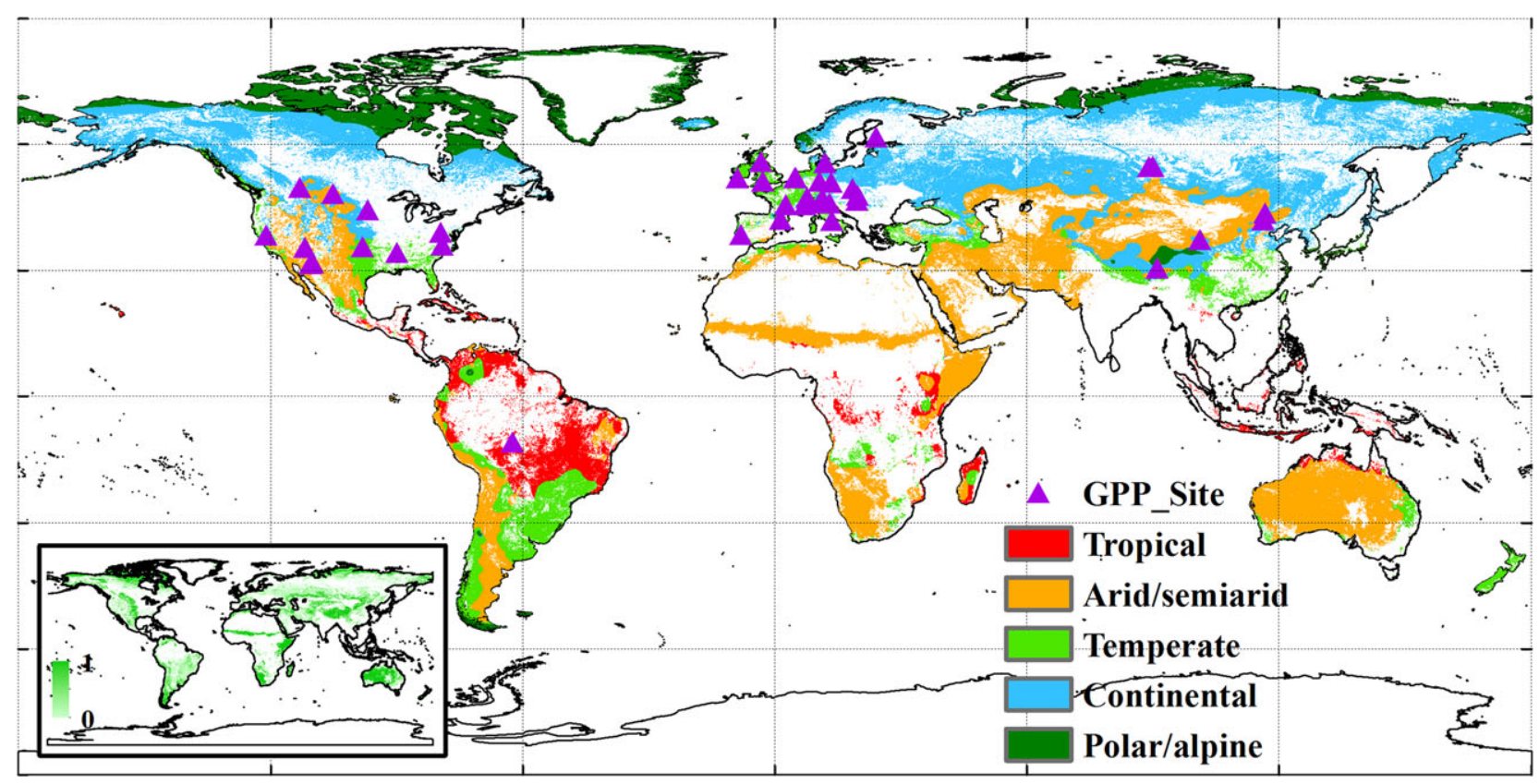

Fig. 2 Map showing locations of the 45 filed plots of grassland gross primary production (GPP) measurements used for MTE-GRASS calibration and validation (a total of 1416 site-months). Different colors indicate different climate zones. The inset map shows the fractions of global grasslands (1/12 degree spatial resolution). [Colour figure can be viewed at wileyonlinelibrary.com].

potential evapotranspiration calculated from these meteorological variables with spatial resolution of $0.5^{\circ} \times 0.5^{\circ}$ during the period 1982-2011 were interpolated from weather station data from Climatic Research Unit (CRU) TS3.1 (Mitchell \& Jones, 2005) and the CRU National Centers for Environmental Prediction (NCEP) product (http://dods.extra.cea.fr/data/ p529viov/cruncep). CRU-NCEP is a climate dataset produced by adding to the CRU TS3.1 monthly climate data from the submonthly normalized variability of the NCEP reanalysis (Kanamitsu et al., 2002).

\section{Site selection for training}

Grassland GPP observations at site level were derived by eddy covariance measurements from 45 flux sites (1416 sitemonths) (Fig. 2), spanning years from 1998 to 2006. These observed data can be obtained from the open access flux database (www.fluxdata.org). The data were processed with standard methodologies, including quality filtering and partitioning of NEE into the two components (GPP and respiration) (Anav et al., 2015). Details about the geographical and climate information of these sites are listed in Table S2.

\section{Other data}

Vegetation-related variables $\left(f_{\mathrm{PAR}}\right)$ with a spatial resolution of $1 / 12$ degree and a temporal resolution of 15 days during the period 1982-2011 are obtained from Zhu et al. (2013). Similar to management data, we extracted grassland $f_{\mathrm{PAR}}$ data at each grid where flux sites are located. World map of Köppen-Geiger climate classification, which is one of the most widely used climate classification systems, was obtained from Kottek et al. (2006). This classification combines average annual and monthly temperature and precipitation, and the seasonality of precipitation (Mcknight \& Hess, 2000). It further divides climates into five main groups, namely tropical, arid/semiarid, temperate, continental, and polar/alpine climate zones (Fig. 2), and each has several subtypes (Table S1). For comparison with the same kind of simulation method of GPP, a global annual GPP product generated by Jung et al. (2011) (hereafter JUNG11) with a spatial resolution of $0.5^{\circ} \times 0.5^{\circ}$ was used. These data were also produced with MTE but without separation of different ecosystems.

\section{Results}

\section{Validation of the MTE-GRASS}

Among site. Figure 3 shows the comparison between the MTE-GRASS and eddy covariance flux measurements in GPP at the monthly and annual scales. In general, on both time scale, the MTE-GRASS performed fairly well in estimating GPP. Specially, at the monthly scale, the estimated GPP was comparable to measured ones in 45 flux towers across 1416 site-months, with a modeling efficiency (NSE) of $0.85, R^{2}$ of 0.85 , and a root-mean-square error (RMSE) of $36.5 \mathrm{~g} \mathrm{C} \mathrm{m}^{-2}$ month ${ }^{-1}$ (Fig. 3a). The mean bias (defined as modeled mean minus observed mean) of the estimated GPP was $0.9 \mathrm{~g} \mathrm{C} \mathrm{m}^{-2}$ month $^{-1}$, suggesting that the MTE-GRASS slightly overestimated GPP in these sites. Statistical 

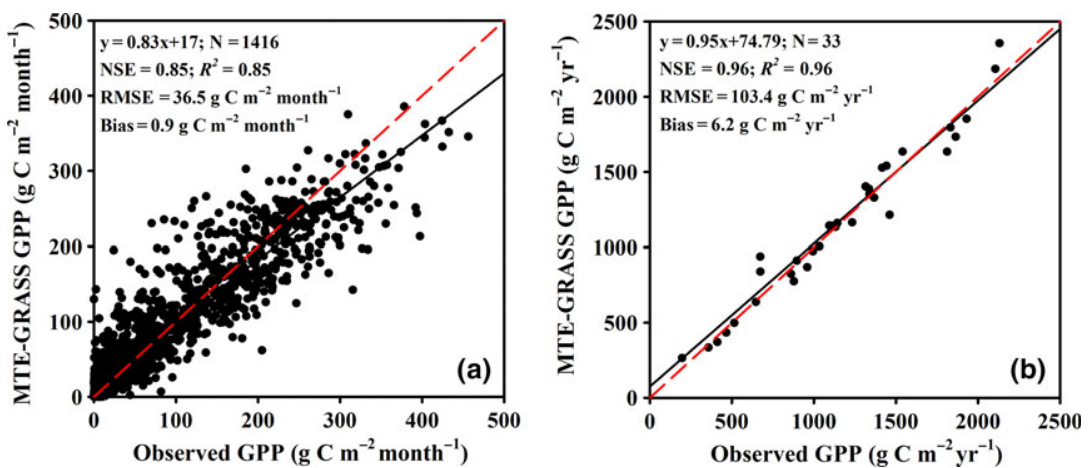

Fig. 3 MTE-GRASS-estimated vs. flux-observed GPP at different time scales: (a) monthly scale and (b) annual scale. [Colour figure can be viewed at wileyonlinelibrary.com].

details of model performance for each site (at least two years must be available) presented in Table S3 showed that the slopes of the linear regressions of the MTEGRASS against observed GPP ranged from 0.21 at USWkg to 1.05 at FR-Lq2 (50\% ranged from 0.8 to 1.0 ), while the intercepts ranged from $-12.34 \mathrm{~g} C$ $\mathrm{m}^{-2}$ month $^{-1}$ at UK-EBu to $56.59 \mathrm{~g} \mathrm{C} \mathrm{m}^{-2}$ month $^{-1}$ at CZ-BK2. NSE ranged from 0.51 to 0.97 , except for CZBK2 and US-Wkg (0.21 and 0.36, respectively); $R^{2}$ ranged from a low of $41 \%$ at US-Wkg to $97 \%$ at CN-HaM. At the annual scale, with a NSE of 0.96 and a $R^{2}$ of 0.96 , the MTE-GRASS was more accurate at reproducing observed GPP (Fig. 3b). Furthermore, our results yielded a RMSE/mean of 9\%, lowering than that from JUNG 11, which includes all ecosystem types (29\%).

Time series. In order to further test the robustness of the MTE-GRASS for estimating GPP in various climate conditions, the comparison between monthly time series of observed GPP and estimated ones in arid/semiarid, temperature, and continental zones was made (each zone was equal-weighted average). As shown in Fig. 4, the time-series variations in GPP of these sites were well captured by the MTE-GRASS, with NSE or $R^{2}$ ranging from 0.69 in arid/semiarid to 0.94 in continental areas and RMSE ranging from $15.8 \mathrm{~g} \mathrm{C} \mathrm{m}^{-2}$ month $^{-1}$ to $18.3 \mathrm{~g} \mathrm{C} \mathrm{m}^{-2}$ month $^{-1}$. This comparison demonstrated that the MTE-GRASS was more consistent for temperate and continental regions (Fig. 4b,c) than that for the arid/semiarid ones (Fig. 4a). This was expected because there were only seven sites (185 site-months) that could be available in arid/semiarid grassland regions. For the other two climate types (i.e., tropics and polar/alpine climate zones), due to the data length limit ( $<2$ years), we could not assess the performance. All in all, the overall good performance, as indicated by higher NSE, $R^{2}$, and lower RMSE and bias, implies a good potential of the MTE-GRASS to be used for analyzing global GPP patterns.

Mean annual and seasonal grassland GPP. Spatial pattern The spatial pattern of mean annual GPP for the period 1982-2011 is shown in Fig. 5a. Overall, global grassland GPP presented a prominent geographical heterogeneity. Annual GPP was generally higher than $1500 \mathrm{~g} \mathrm{C} \mathrm{m}^{-2} \mathrm{yr}^{-1}$ in southern Brazil where the climate was characterized with abundant precipitation and warm temperature (Fig. S2a,f). In comparison, lowest values $\left(<50 \mathrm{~g} \mathrm{C} \mathrm{m}^{-2} \mathrm{yr}^{-1}\right)$ were found in Arctic and Tibetan Plateau as a result of low temperature or limited SWrad (Fig. S2k), or areas with relatively lower precipitation amount limiting the vegetation production, especially in Saudi Arabia, Iran, southwestern South Africa, Australia and a west-to-east band below the Sahara. Moreover, a typical longitudinal gradient in northern Eurasia with GPP decreasing toward the east was detected, which is related to increasingly continental climate (Beer et al., 2010).

The seasonal spatial patterns of GPP were similar to those on the annual scale but with different magnitudes (Fig. 5b-e). North America and Eurasia (except southwestern Asia) experienced distinct seasonal changes, with higher value (above $200 \mathrm{~g} \mathrm{C} \mathrm{m}^{-2} \mathrm{yr}^{-1}$ ) during JJA (June, July, and August) and lower value (near-zero) during DJF (December, January, and February) when precipitation and temperature do not benefit vegetation growth (Fig. S2e,j). Further support can be found by analyzing $f_{\mathrm{PAR}}$ value, being minimal during DJF in these regions. During MAM (March, April, and May) and SON (September, October, and November), grassland GPP was also relatively small in the Northern Hemisphere $(\mathrm{NH})$, reflecting foliage phenology to a certain extent. In contrast, no obvious seasonal cycles were observed in the Southern 

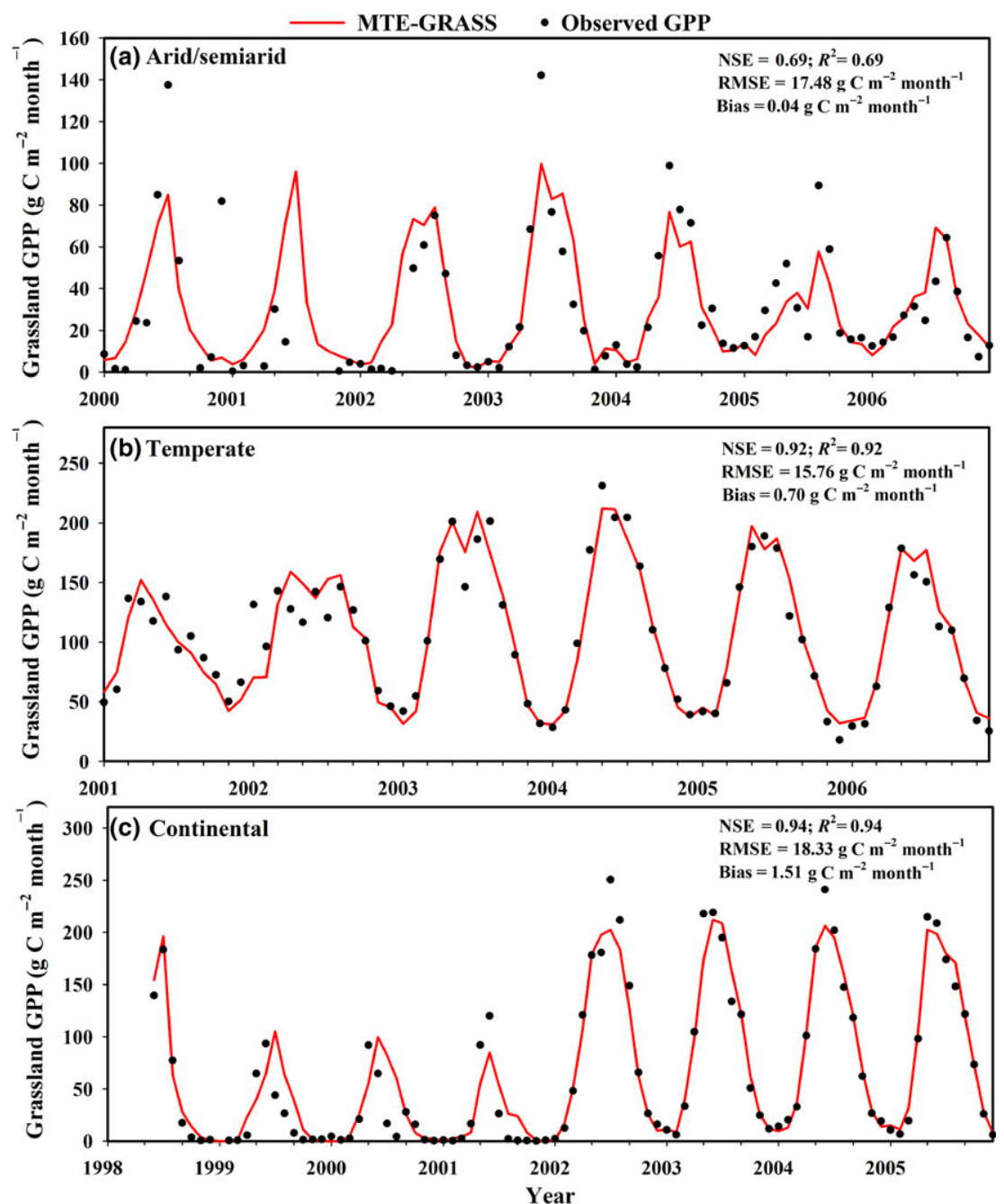

Fig. 4 Monthly time-series comparisons between MTE-GRASS-estimated and flux-observed GPP in different climate conditions: (a) arid/semiarid; (b) temperate; and (c) continental. [Colour figure can be viewed at wileyonlinelibrary.com].

Hemisphere (SH), including South America, central and southern Africa, and Australia. Moreover, except for Chile, GPP was high (above $300 \mathrm{~g} \mathrm{C} \mathrm{m}^{-2} \mathrm{yr}^{-1}$ ) throughout the whole year in the South America. Higher GPP was also found in Madagascar during DJF and New Zealand during SON (Fig. 5d,e).

Different climate zones. Using the MTE-GRASS, we calculated the annual average GPP of global grasslands over the past 30 years. The average annual global GPP from 1982 to 2011 was $532 \pm 11 \mathrm{~g} \mathrm{C} \mathrm{m}^{-2} \mathrm{yr}^{-1}$ or a total amount of $11 \pm 0.3 \mathrm{Pg} \mathrm{C} \mathrm{yr}^{-1}$, accounting for $9 \%$ of the total global GPP $\left(119 \pm 0.3 \mathrm{Pg} \mathrm{yr}^{-1}\right)$ given in Jung et al. (2011) and recent multimodel analysis based on flux data of $123 \pm 8 \mathrm{Pg} \mathrm{C} \mathrm{yr}^{-1}$ (Beer et al., 2010). At the seasonal scale, the average annual (1982-2011) GPP during MAM, JJA, SON, and DJF was 2.82 Pg C, 4.10 Pg C, 2.37 $\mathrm{Pg} \mathrm{C}$, and 2.11 Pg C, respectively.

For different climate zones (Fig. 5f), it was shown that temperate regions account for the largest proportion of the total global GPP $\left(26 \%, 2.98{\left.\mathrm{Pg} \mathrm{C} \mathrm{yr}^{-1}\right)}^{-1}\right.$ at the

Fig. 5 (Left) spatial distributions of average annual and seasonal global GPP, and (right) GPP of each climate zone (including tropical (TROP), arid/semiarid (ARSR), temperate (TEMP), continental (CONT), and polar/alpine (POAL)), and its contribution to global GPP during the period 1982-2011. (a and f) Annual; (b and g) March, April, and May (MAM); (c and h) June, July, and August (JJA); (d and i) September, October, and November (SON); and (e and g) December, January, and February (DJF). The inset shows the frequency. [Colour figure can be viewed at wileyonlinelibrary.com]. 


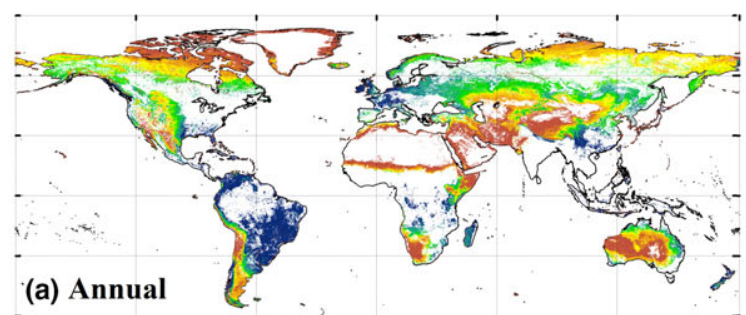

(a) Annual

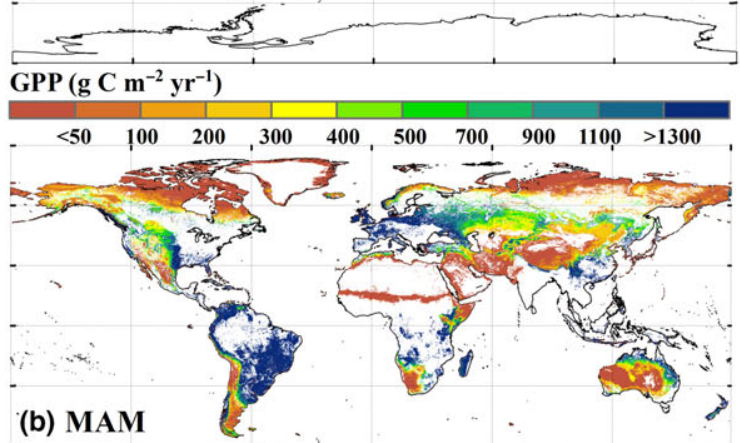

(b) MAM
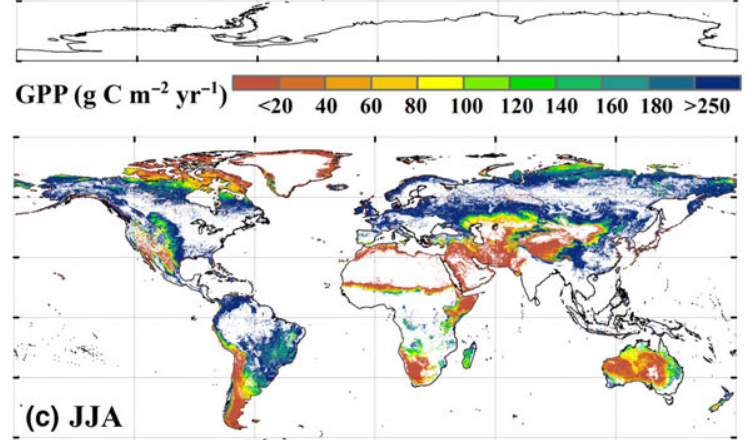

\section{(c) JJA}

(
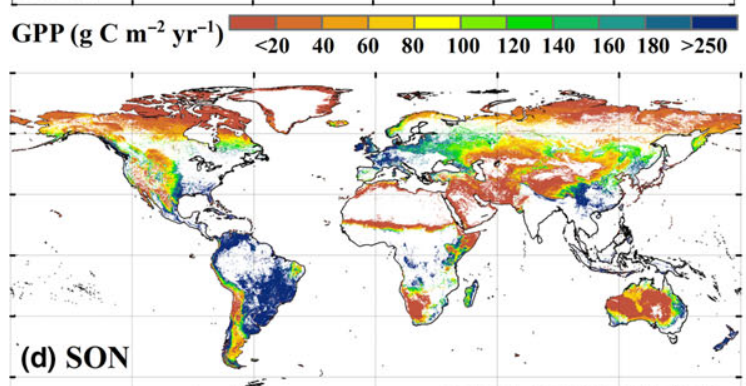

(d) SON

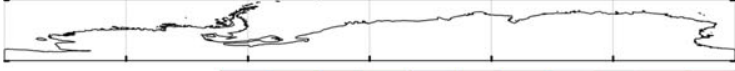

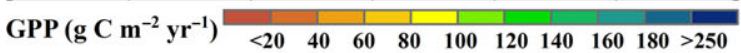

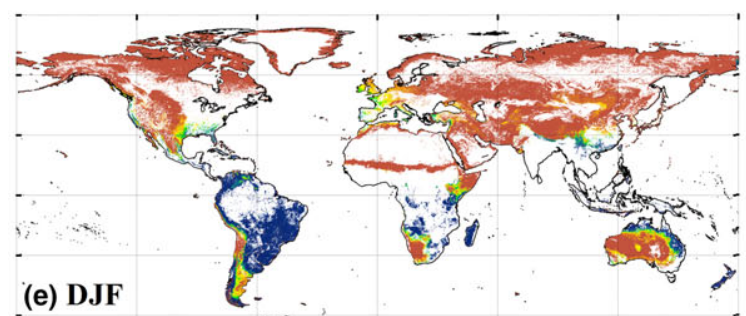

(e) DJF

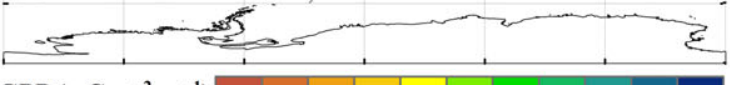

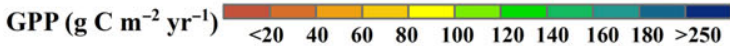
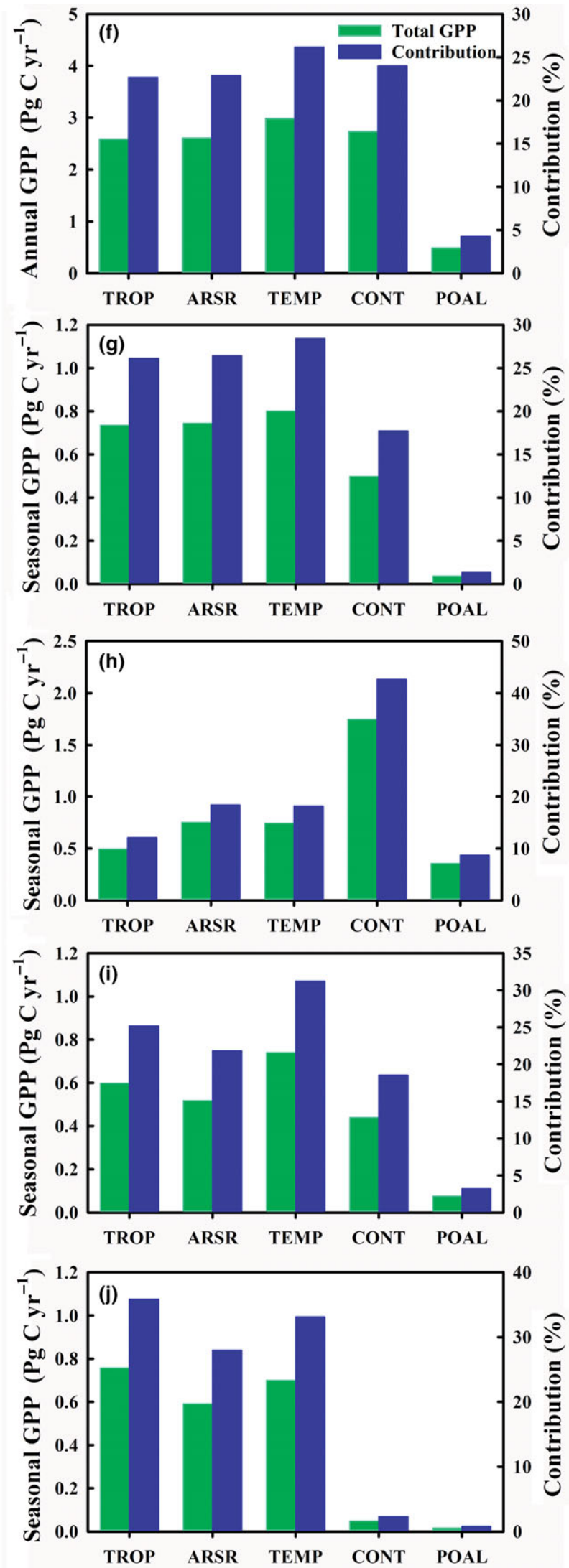

(C) 2017 John Wiley \& Sons Ltd, Global Change Biology, 23, 2720-2742 
annual scale. Continental regions had the second largest GPP $\left(24 \%, 2.73 \mathrm{Pg} \mathrm{C} \mathrm{yr}^{-1}\right)$, followed by arid/semi-

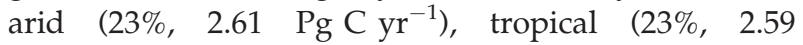
$\left.\mathrm{Pg} \mathrm{C} \mathrm{yr}^{-1}\right)$, and polar/alpine climate zones (4\%, 0.49 $\left.\mathrm{Pg} \mathrm{C} \mathrm{yr}^{-1}\right)$. However, in terms of GPP flux, the highest GPP occurred in tropics, with an average annual value of $1648 \mathrm{~g} \mathrm{C} \mathrm{m}^{-2} \mathrm{yr}^{-1}$, which is seven times of that in arid/semiarid regions (223 $\mathrm{g} \mathrm{C} \mathrm{m}^{-2} \mathrm{yr}^{-1}$ ). As expected, polar/alpine had the lowest annual GPP (133 $\mathrm{g}$ $\mathrm{C} \mathrm{m}^{-2} \mathrm{yr}^{-1}$ ), which can be mainly related to the lower temperature in the region (Fig. S2f). Arid/semiarid regions had a relatively lower GPP, but considering total amount, it had higher GPP which can primarily lie in the large area $\left(1.3 \times 10^{7} \mathrm{~km}^{2}, 50 \%\right.$ of the global total grasslands area). In addition, distinct seasonal cycles of GPP could be found in continental regions. For example, mean annual GPP from this region during JJA was $1.75 \mathrm{Pg} \mathrm{C} \mathrm{m}{ }^{-2} \mathrm{yr}^{-1}$, while this value was only 0.05 $\mathrm{Pg} \mathrm{C} \mathrm{m}{ }^{-2} \mathrm{yr}^{-1}$ during DJF (Fig. 5g,j).

\section{Changes in grassland GPP}

GPP Trends. Figure 6 shows the spatial distributions of the GPP trends for the past 30 years. About $68 \%$ of the pixels showed an increasing trend in GPP, with $28 \%$ being significant (Table S4). The highest increase in GPP occurred in the high-latitude regions of the NH $\left(>60^{\circ} \mathrm{N}\right)$, the Rocky Mountains, western Europe, west-to-east band below the Sahara, northwestern and southeastern China, and northern Australia (Fig. 6a). In contrast, only $32 \%$ of the pixels showed a decreasing trend, mainly in South America, central Eurasia, and southeastern Africa. For pixels showing decreasing trends in GPP, only about 7\% have statistically significant values $(P<0.05)$ (Table S4). However, after normalizing the trends by their mean value, more obvious increasing trend (over $0.05 \%$ per year on average) were observed in relative drier regions, that is, southern Africa, central western Asia, and the majority of Australia (Fig. 6h), suggesting that arid/semiarid regions had the largest increasing rate in GPP.

At the seasonal scale, positive trends were found about $70 \%, 59 \%, 63 \%$, and $56 \%$ pixels for MAM, JJA, SON, and DJF, respectively (Table S4). Negative trends were detected for all seasons over central South America. During MAM, positive trends of larger than 2 $\mathrm{g} \mathrm{C} \mathrm{m}^{-2} \mathrm{yr}^{-2}$ mainly concentrated in the southern of South America, western Europe and western Turkey, the area between Black Sea and Caspian Sea, southern China, and northern Australia (Fig. 6b). During JJA, both negative and positive trends were found, with $20 \%$ of grid cells having significantly $(P<0.05)$ positive trends and $9 \%$ significantly negative trends (Table S4). High northern latitude regions and central western
America have the largest increase in GPP (>2 $\mathrm{g} \mathrm{C} \mathrm{m}^{-2} \mathrm{yr}^{-1}$ ). By contrast, the largest decline was in GPP mainly located in central Eurasia and Texas (Fig. 6c). In SON and DJF, except for South America, southern Africa, and northeastern Australia, most areas around the world have relatively flatter increase in GPP (Fig. 6d,e).

The annual total global terrestrial grassland GPP presented an increasing trend from 1982 to 2011 (Fig. 7a),

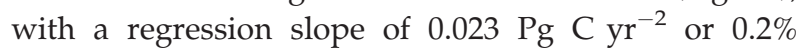
$(P<0.0001)$, accounting for about $25 \%$ of trend in global GPP including all biomes from JUNG11 (0.094 $\mathrm{Pg} \mathrm{C} \mathrm{yr}^{-2}$ ). The overall significantly increasing trends in GPP were also consistent among different climate zones (except tropical regions), but with different changing rate (Fig. 7f). The largest positive trend in GPP was found in arid/semiarid climatic zones $(0.012$ $\mathrm{Pg} \mathrm{C} \mathrm{yr}^{-2}$ ), which accounted for $54 \%$ of the global increase in GPP, exceeding continental $(0.006$ $\left.\mathrm{Pg} \mathrm{C} \mathrm{yr}{ }^{-2}, 27 \%\right)$, polar/alpine (0.003 $\left.\mathrm{Pg} \mathrm{C} \mathrm{yr}^{-2}, 11 \%\right)$, and temperate ones $\left(0.002 \mathrm{Pg} \mathrm{C} \mathrm{yr}^{-2}, 9 \%\right)$. For tropical regions, a slightly nonsignificantly decreasing trend was observed $\left(-0.0002 \mathrm{Pg} \mathrm{C} \mathrm{yr}^{-2}\right)$. Nevertheless, in terms of the increasing rate (normalized by the mean value through the time series), polar/alpine and arid/ semiarid regions showed the largest values by $0.50 \%$ and $0.48 \%$ per year, respectively. Continental zones had the third increasing rate $(0.22 \%)$, followed by temperate $(0.07 \%)$ and tropical areas $(-0.01 \%)$.

For different seasons (Fig. $7 \mathrm{~b}-\mathrm{e}$ ), it showed a significantly positive trend $(P<0.05)$ during all seasons at the global scale, with an annual increasing rate of 0.007 $\mathrm{PgC} \mathrm{yr}^{-1}, 0.007 \mathrm{PgC} \mathrm{yr}^{-1}, 0.004 \mathrm{Pg} \mathrm{C} \mathrm{yr}^{-1}$, and 0.004 $\mathrm{Pg} \mathrm{C} \mathrm{yr}^{-1}$ for MAM, JJA, SON, and DJF, respectively. In other words, $63 \%$ of global GPP increase comes from MAM and JJA. Moreover, similar to that in the annual scale, arid/semiarid climate zones dominated the global GPP increasing trend in all seasons (average 66\%), particularly for DJF (87\%), except for JJA in which continental areas dominated this increasing trend (47\%). Further analysis showed that global annually positive trend in GPP was primarily attributed to arid/semiarid ecosystems in MAM and DJF ( $33 \%$ in total). In addition, polar/alpine showed the largest increasing rate at an average rate of $0.54 \%$ per year in all seasons (Fig. $7 \mathrm{~g}-\mathrm{i}$ ), except for the winter season (DJF) in the $\mathrm{NH}$.

Interannual variability in GPP. Here, we used the coefficient of variation $(\mathrm{CV})$ to indicate the magnitude of GPP's IAV during 1982-2011. As shown in Fig. 8a, GPP had a higher IAV in Mexico, Africa, southwestern Asia, and Australia (above 0.50 on average), while other regions had a relatively lower IAV of below 0.15. JJA reproduced the same spatial pattern, but with a lower 

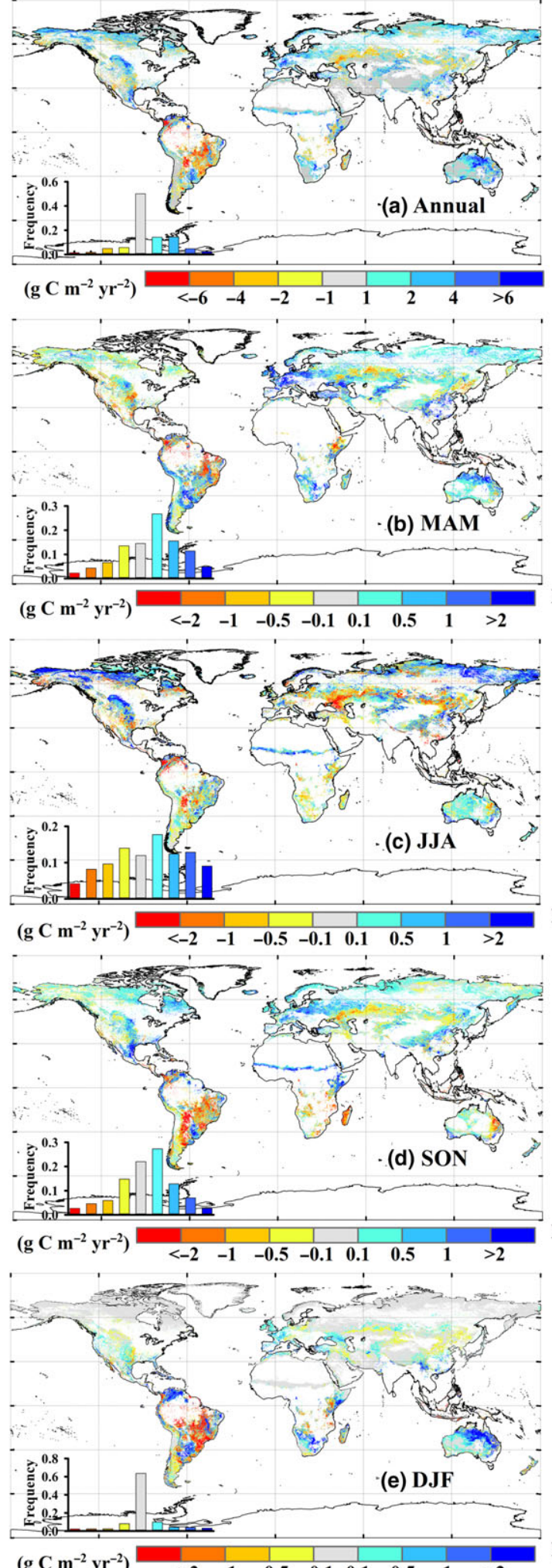

$\begin{array}{lllllllllll}\left(\mathrm{g} \mathrm{C} \mathrm{m}^{-2} \mathrm{yr}^{-2}\right) & <-2 & -1 & -0.5 & -0.1 & 0.1 & 0.5 & 1 & >2\end{array}$

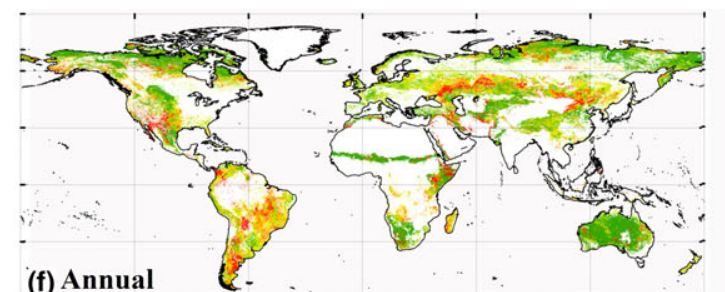

(f) Annual
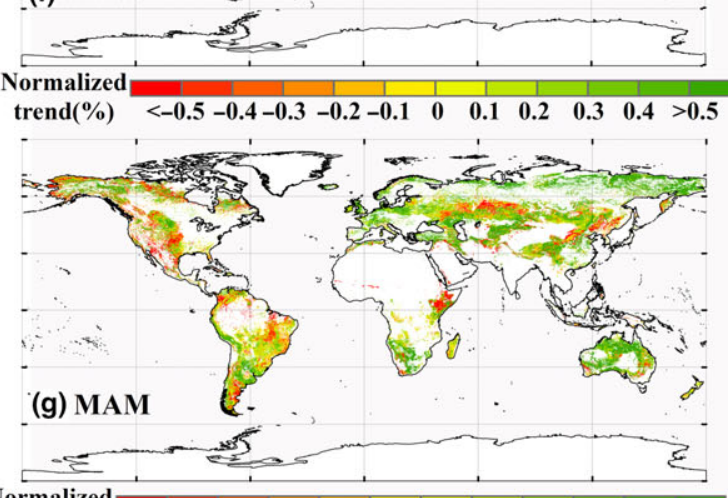

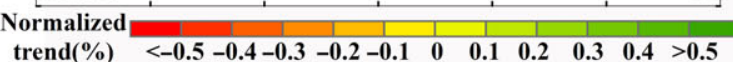

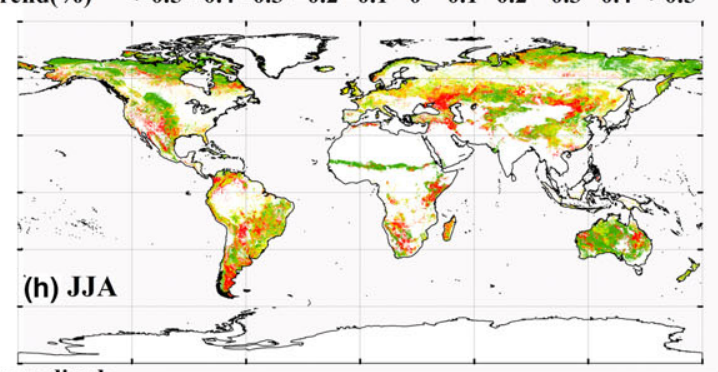

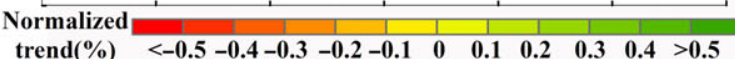

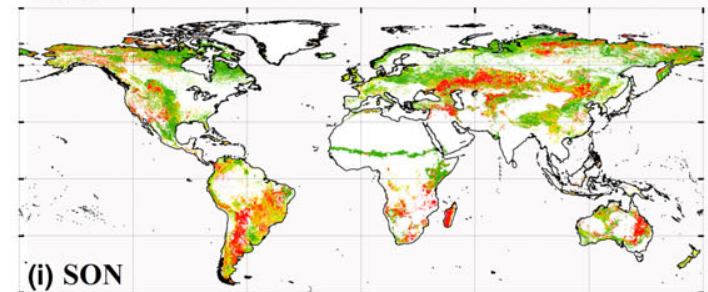

(i) SON

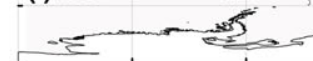

trend(\%) $<-0.5-0.4-0.3-0.2-0.1 \quad 0 \quad 0.1 \quad 0.2 \quad 0.3 \quad 0.4>0.5$

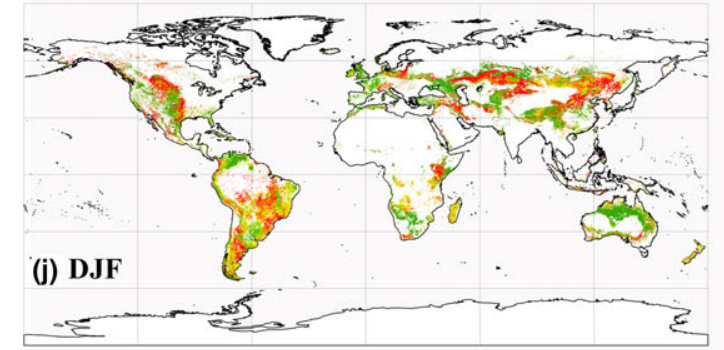

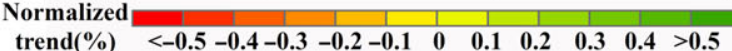

Fig. 6 Spatial distributions of annual and seasonal trends in global grassland GPP during the period 1982-2011. Right panels (f-j) are normalized trend (normalized by the mean value through the time series). The inset shows the frequency. [Colour figure can be viewed at wileyonlinelibrary.com]. 

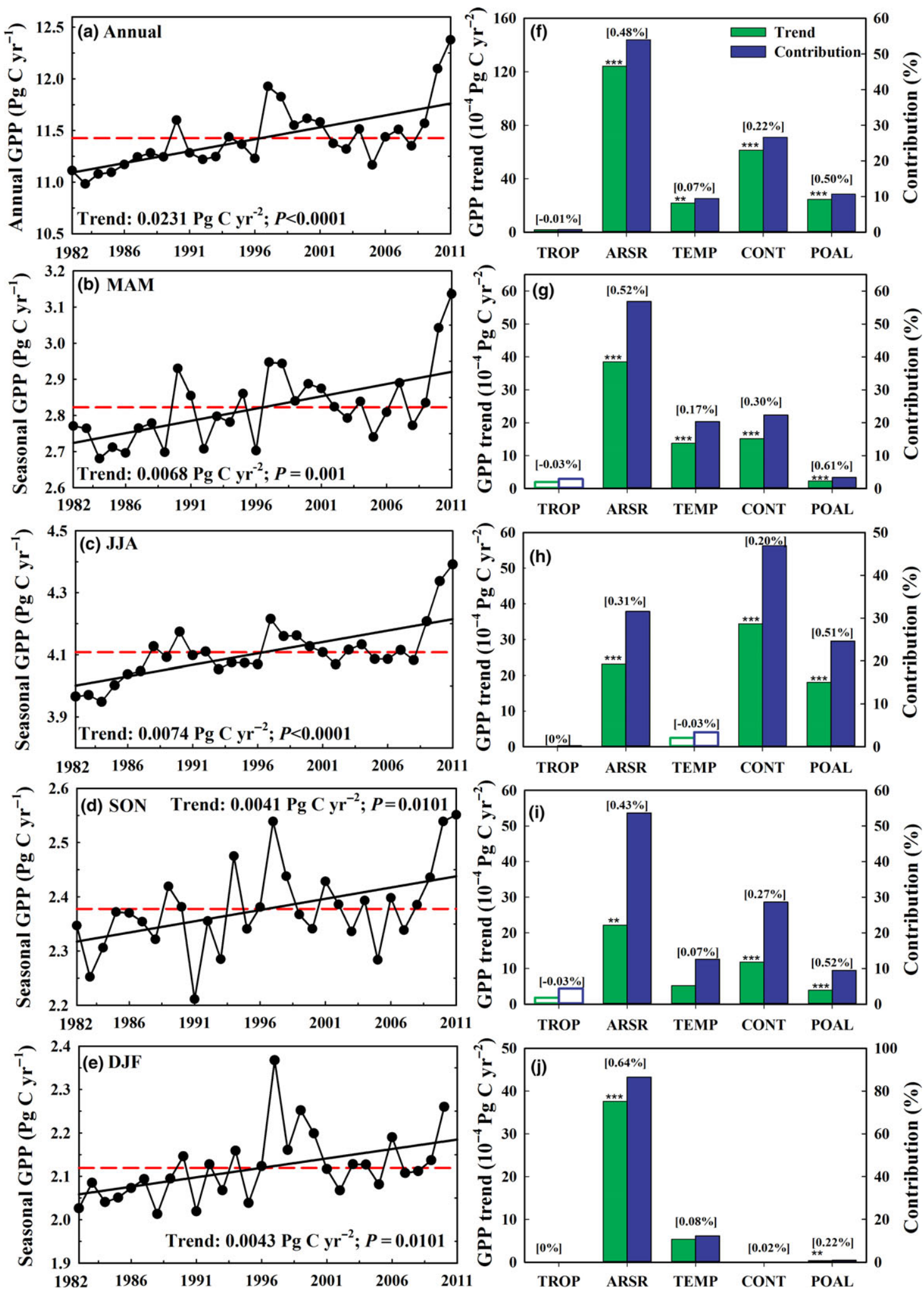

Fig. 7 (Left) interannual variations in total terrestrial grassland GPP during the period 1982-2011, and (right) GPP trends in each climate zone and its contributions to global GPP. (a and f) Annual; (b and g) MAM; (c and h) JJA; (d and i) SON; and (e and g) DJF. The numbers in brackets are normalized trend. ${ }^{* *} P<0.01 ; * P<0.05$. Trend with no asterisk is not significant $(P>0.1)$. [Colour figure can be viewed at wileyonlinelibrary.com]. 


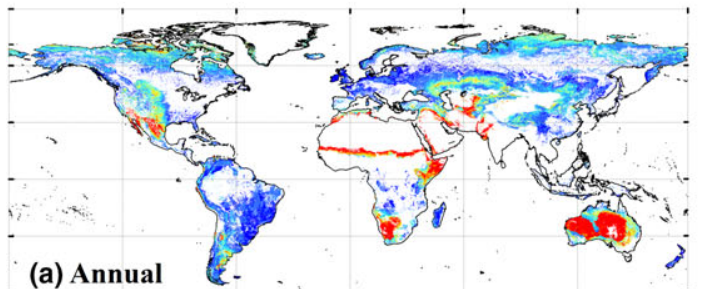

(a) Annual

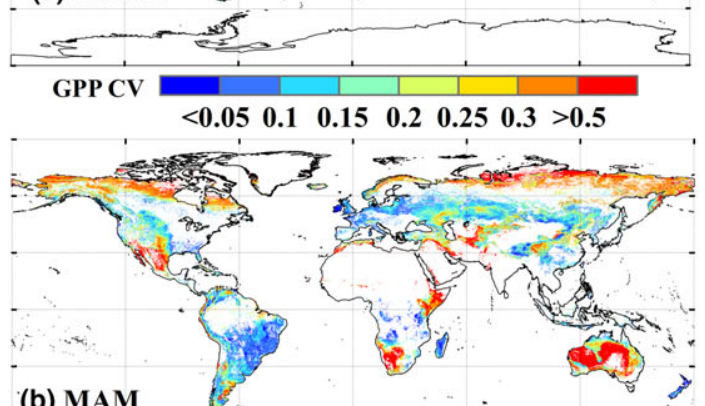

(b) MAM

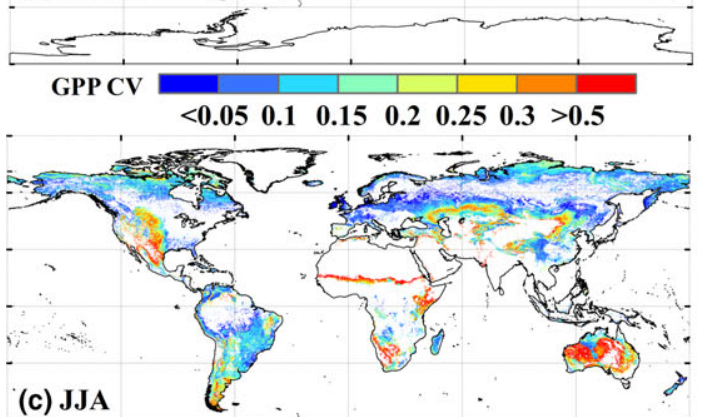

(c) JJA

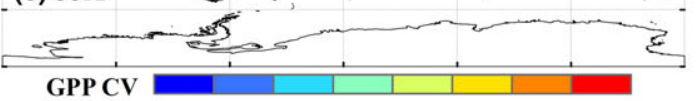

$\begin{array}{lllllll}<0.05 & 0.1 & 0.15 & 0.2 & 0.25 & 0.3 & >0.5\end{array}$

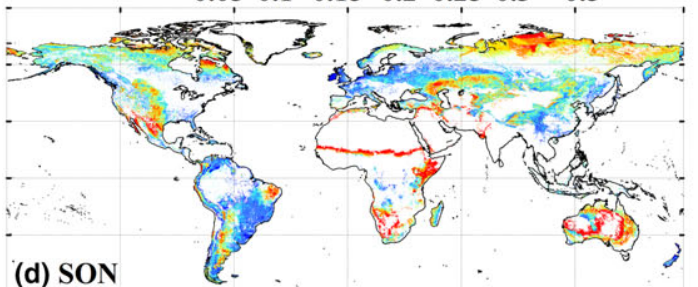

(d) SON

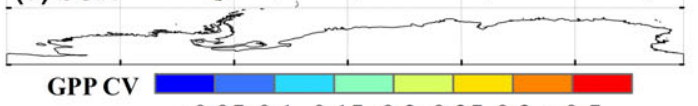

$\begin{array}{lllllll}<0.05 & 0.1 & 0.15 & 0.2 & 0.25 & 0.3 & >0.5\end{array}$

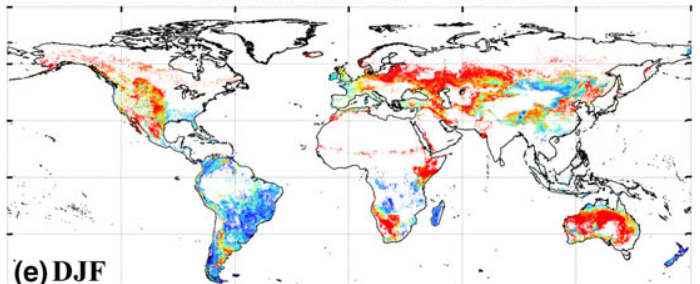

(e) DJF

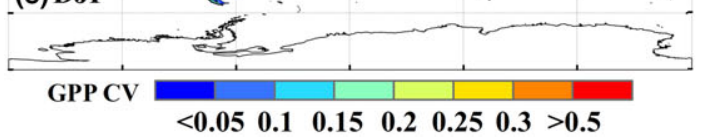

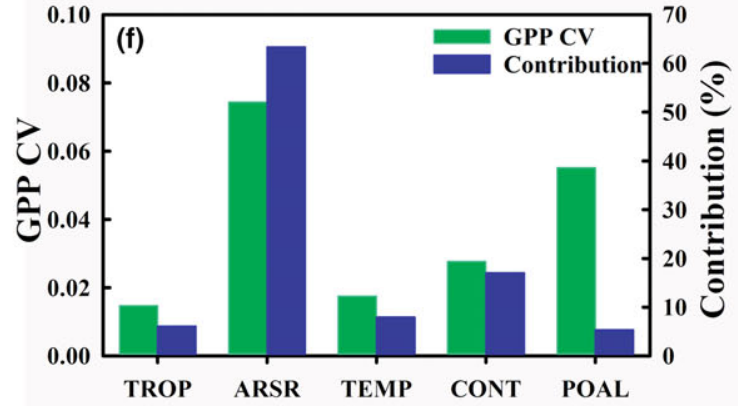
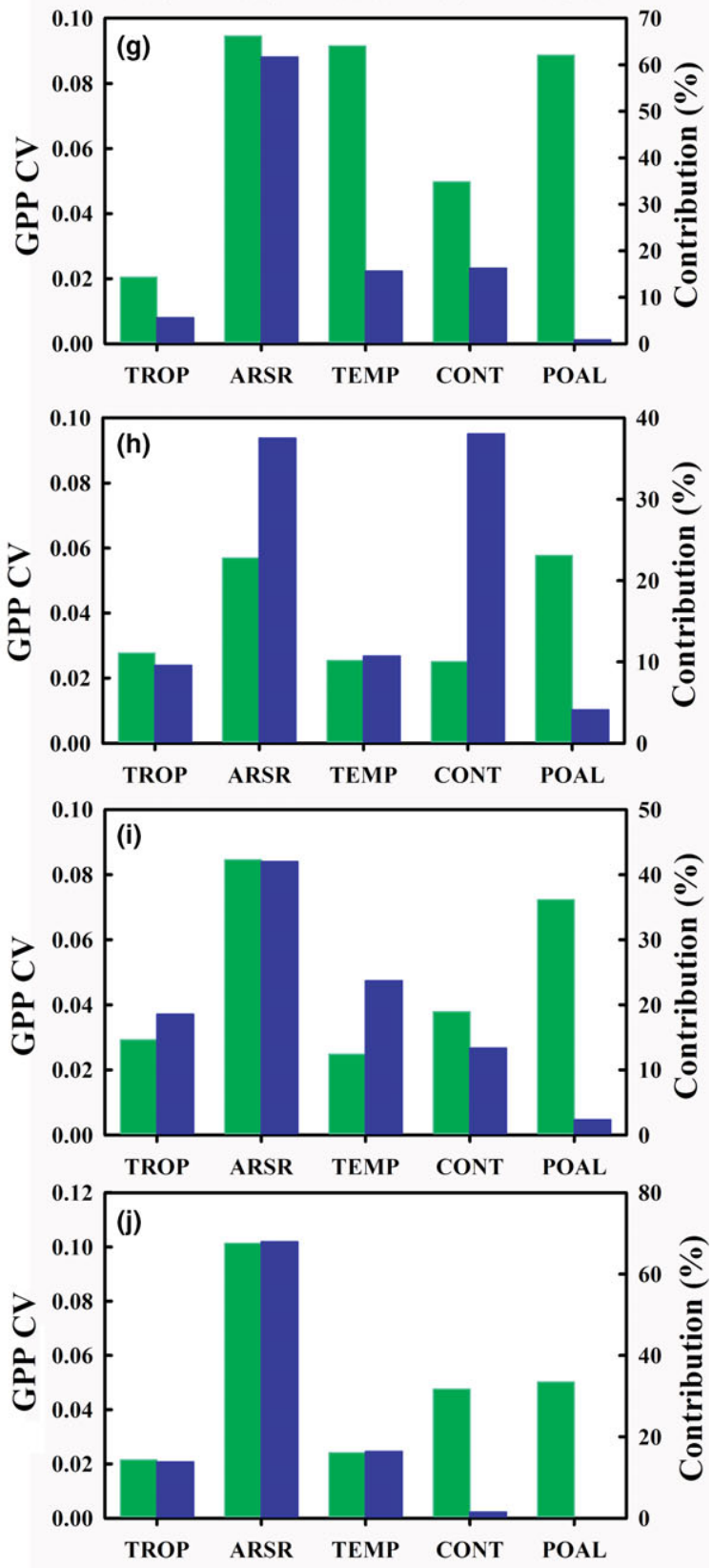

Fig. 8 (Left) spatial distributions of average annual and seasonal coefficient of variation (CV) for global GPP, and (right) for each climate zone and its contribution to global GPP IAV during the period 1982-2011. (a and f) Annual; (b and g) MAM; (c and h) JJA; (d and i) SON; and (e and g) DJF. [Colour figure can be viewed at wileyonlinelibrary.com]. 
magnitude in the variability (Fig. 8c). Similarly, MAM and SON shared the same pattern with higher IAV in the high latitude of the $\mathrm{NH}$, Mexico, Africa, and Australia, while lower IAV in South America and central Eurasian continent (Fig. 8b,d). For the winter in the NH (Fig. 8e), except for South America, some areas in Africa and northern China, almost the whole world, experienced a higher IAV $(\mathrm{CV}>0.3)$.

For different climate zones, IAV was generally lower in tropics than that in arid/semiarid and polar/alpine regions. At the annual time scale (Fig. 8f), arid/semiarid areas had the highest IAV $(\mathrm{CV}=0.07)$ and accounted for the largest fraction, 63\%, of global GPP IAV (methods). Similar results could be almost obtained from the seasonal scale (Fig. $8 \mathrm{~g}-\mathrm{j}$ ), suggesting arid/semiarid vegetation production emerges clearly as the most important factor driving global grassland GPP IAV. By contrast, although polar/alpine regions had higher GPP IAV, its contribution to global one was the lowest, which could be related to the lower amount of GPP. Furthermore, as a result of monsoon circulation, GPP IAV of continental areas during JJA acted almost equal role in driving global GPP IAV with that of arid/ semiarid zones (38\%).

\section{GPP in relation to climatic factors}

Interannual control. In order to further investigate the interannual controls of grassland GPP by climate, a partial correlation analysis between annual GPP series and climatic variables during the period 1982-2011 was conducted. As illustrated in Fig. 9a, there was positive partial correlation coefficient $(r)$ between GPP and precipitation at $37 \%$ of pixels $(P<0.05)$. The highest positive $r$ values are primarily in Australia, southern South America, southwestern North America, Africa, central of Asia, and southern Europe. Compared with precipitation, temperature was positively correlated with GPP in the cold regions, for example, northern Canada, Siberia, and areas around the Tibetan Plateau, because boreal and arctic ecosystems are cold and rarely water limited (Piao et al., 2014). In addition, tundra ecosystem in the high latitudes appeared to be colimited by temperature and SWrad (Fig. 9d). A summary of the dominant climatic driving factors with the largest positive $r$ value showed that precipitation is the dominant control of GPP variability of $51 \%$ pixels. In comparison, temperature and SWrad control 31\% pixels and $18 \%$ pixels, respectively.

Figure 10 shows the correlation analysis between annual GPP series and climate variables for each climate zone of 1982-2011. Averaged over the whole world, results showed that annual GPP was positively correlated with annual precipitation $(r=0.21)$, whereas the $r$ between annual GPP and temperature and SWrad was only 0.04 and -0.02 , respectively, suggesting that the interannual variation in temperature and SWrad has limited effects on that in GPP globally. However, the relationships between annual GPP and climate variables vary greatly among climate zones. Precipitation was the major controlling factor on interannual variation in GPP in arid/semiarid $(r=0.47)$ and temperate $(r=0.2)$ ecosystems, whereas temperature showed significant $(P<0.05)$ and positive correlation with GPP in polar/alpine regions. Furthermore, in tropical regions, all climatic variables (precipitation, temperature, and SWrad) present negative correlation with GPP. This may arise from the fact that nutrient availability acts as a crucial role in promoting plant growth in areas without water and temperature stresses (Donohue et al., 2009; Yang et al., 2016a).

Response of GPP to climate. To investigate the response of GPP to climate change, the sensitivity of GPP to climate change was quantified as the slope of the linear regression function. It should be noted that only pixels with significant $r(P<0.05)$ between GPP and climate variables are considered in this analysis. As illustrated in Fig. 11a, in general, an increase in annual precipitation by $100 \mathrm{~mm}$ will result in an increase of $26 \mathrm{~g} \mathrm{C} \mathrm{m}^{-2} \mathrm{yr}^{-1}$ in GPP with arid/semiarid regions increasing $33 \mathrm{~g} \mathrm{C} \mathrm{m}^{-2} \mathrm{yr}^{-1}$ compared to a decrease of $-9 \mathrm{~g} \mathrm{C} \mathrm{m}^{-2} \mathrm{yr}^{-1}$ in the tropics. In comparison, an increase in annual mean temperature by $1{ }^{\circ} \mathrm{C}$ will cause a $13 \mathrm{~g} \mathrm{C} \mathrm{m}^{-2} \mathrm{yr}^{-1}$ decrease in GPP (Fig. 11b). The highest negative temperature sensitivity was observed in tropical regions, with $1{ }^{\circ} \mathrm{C}$ increase in temperature relating to $73 \mathrm{~g} \mathrm{C} \mathrm{m}^{-2} \mathrm{yr}^{-1}$ decrease in GPP, followed by $59 \mathrm{~g} \mathrm{C} \mathrm{m}^{-2} \mathrm{yr}^{-1}$ in arid/semiarid and $6 \mathrm{~g} \mathrm{C} \mathrm{m}^{-2} \mathrm{yr}^{-1}$ in temperate regions. However, for other climate regions, an increase in annual mean temperature by $1{ }^{\circ} \mathrm{C}$ in continental and polar/alpine regions would lead to an increase in GPP by $18 \mathrm{~g} \mathrm{C} \mathrm{m}^{-2} \mathrm{yr}^{-1}$ and $13 \mathrm{~g} \mathrm{C} \mathrm{m}^{-2} \mathrm{yr}^{-1}$, respectively. In comparison with precipitation and temperature, GPP was correlated with SWrad at much fewer areas (9\% of pixels). Results showed that averaged over all climate zones, an increase in annual SWrad by $100 \mathrm{MJ}$ will cause a $28 \mathrm{~g} \mathrm{C} \mathrm{m}^{-2} \mathrm{yr}^{-1}$ decrease in GPP (Fig. 11c). This overall negative sensitivity between SWrad and GPP is largely driven by the arid/semiarid and temperate regions $\left(38 \mathrm{~g} \mathrm{C} \mathrm{m}^{-2} \mathrm{yr}^{-1}\right.$ and $25 \mathrm{~g} \mathrm{C} \mathrm{m}^{-2} \mathrm{yr}^{-1}$ decrease in GPP by a 100 MJ increase in SWrad, respectively), whereas GPP-SWrad relationship was found positive. The highest positive SWrad sensitivity was observed in tropics $\left(\left(48 \mathrm{~g} \mathrm{C} \mathrm{m}^{-2} \mathrm{yr}^{-1}\right) / 100 \mathrm{MJ}\right)$, followed in a descending order by polar/alpine 


\section{(a) Annual GPP-Annual Precipitation}

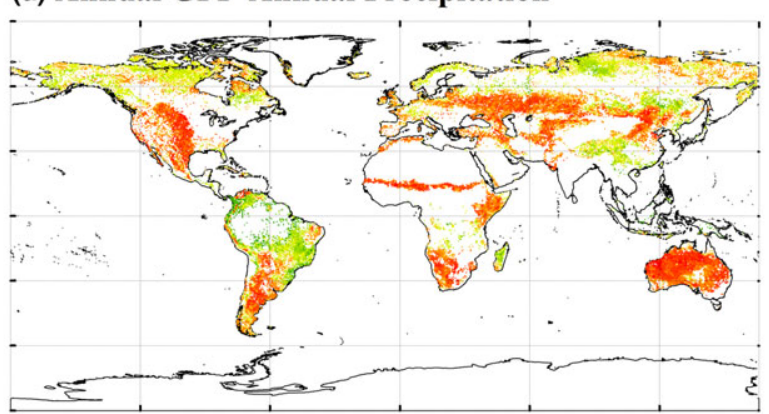

(c) Annual GPP-Annual SWrad

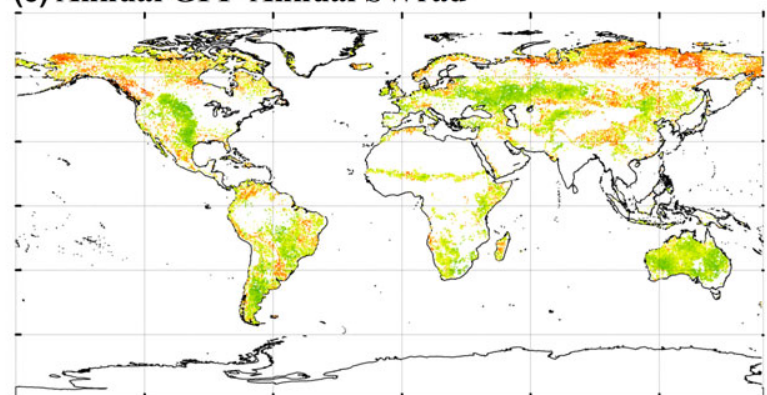

(r)

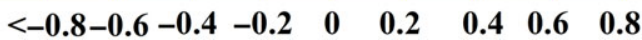

(b) Annual GPP-Annual Mean Air Temperature

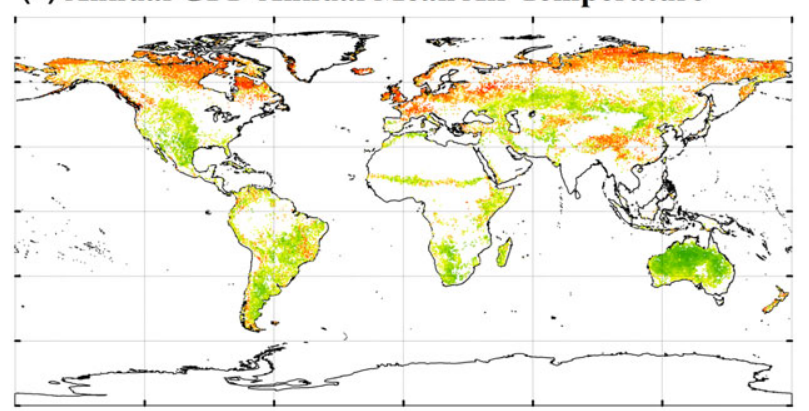

(d) Control factor

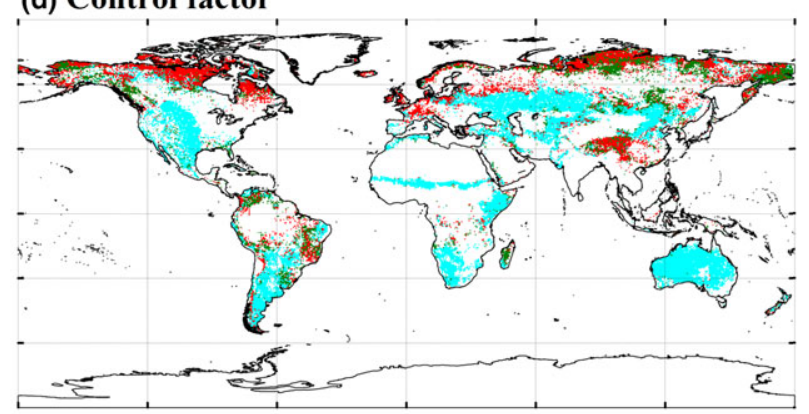

Precipitation

SWrad

Fig. 9 Interannual partial correlation coefficients $(r)$ between GPP and (a) precipitation; (b) mean air temperature; and (c) short-wave radiation (SWrad) during the period 1982-2011. (d) Interannual variation in GPP of the dominant climatic driving factors with the largest positive $r$ value. [Colour figure can be viewed at wileyonlinelibrary.com].

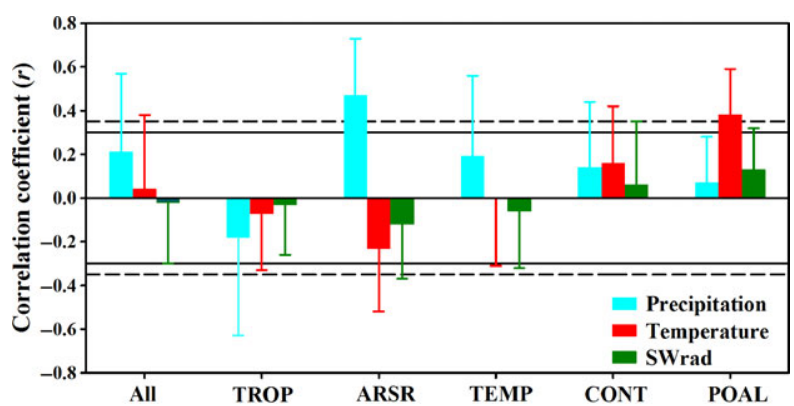

Fig. 10 Correlation coefficient $(r)$ between GPP and precipitation, temperature, and SWrad at the annual scale for individual climate zone. [Colour figure can be viewed at wileyonlinelibrary.com].

((38 $\left.\left.\mathrm{g} \mathrm{C} \mathrm{m}^{-2} \mathrm{yr}^{-1}\right) / 100 \mathrm{MJ}\right)$ and continental areas $\left(\left(9 \mathrm{~g} \mathrm{C} \mathrm{m}^{-2} \mathrm{yr}^{-1}\right) / 100 \mathrm{MJ}\right)$. Moreover, spatial variability in each zone was also obvious as indicated by higher standard deviation.

Because precipitation played an important role in governing global GPP IAV, to further explore the GPPprecipitation relationship at shorter time scale, we conducted time lag analysis between precipitation and GPP in month scale. Results showed that, for most regions, the maximum correlation was obtained when precipitation is concurrent with GPP or preceded GPP by 1 month (Fig. 12). Larger time lags (lag $\geq 3$ months) corresponded to maximum correlations in the high latitude of the NH, northern South America, and southern China where temperature variation is the major driving factor in these regions.

For individual climate zone, correlation coefficients (r) varied considerably with different time lags (Fig. 13). In tropics, time lag results showed that negative correlation was mostly strong when precipitation was concurrent with GPP. This may stem from the fact that tropical grasslands is primarily distributed in northern South America (as shown in Fig. 2), where climate is characterized with high annual precipitation. More precipitation would usually result in a reduction in incoming solar radiation (Piao et al., 2014). Further support can be found in the negative GPP-precipitation relationship (Fig. 10). By contrast, in precipitation-dominated regions, that is, continental, arid/semiarid, and temperature areas, the maximum correlation was obtained when precipitation preceded GPP by 1 month or was concurrent with GPP (no time lag), indicating that grasslands in these areas responded to precipitation were more 


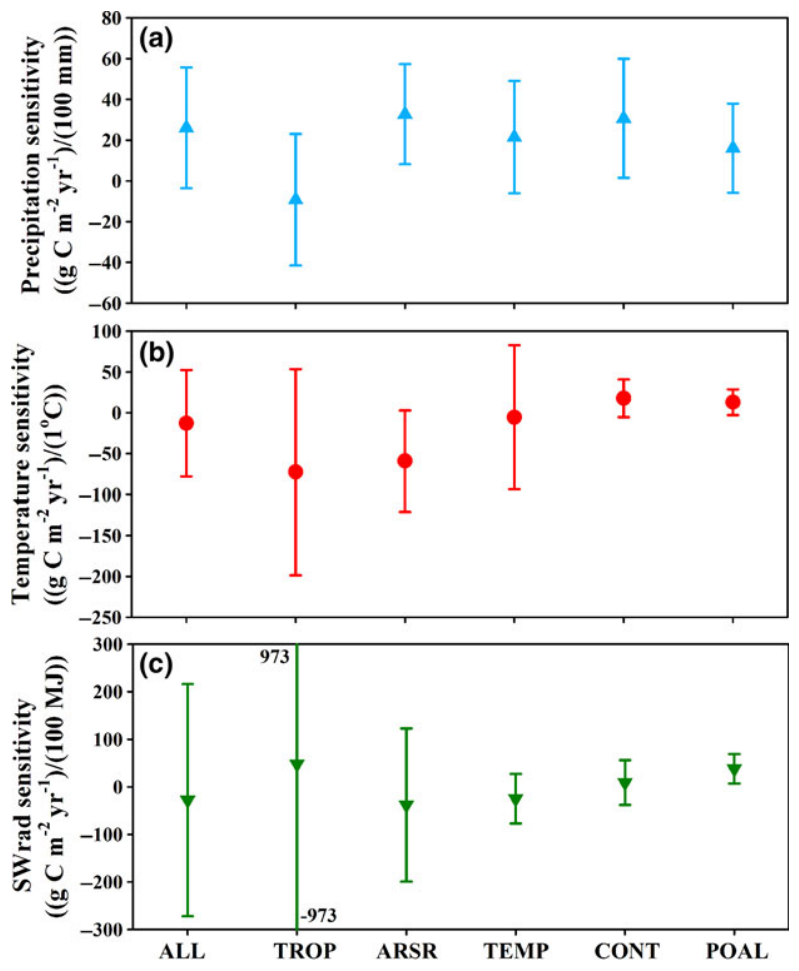

Fig. 11 GPP sensitivity to (a) precipitation variability; (b) temperature variability; and (c) SWrad variability in different climate zones. [Colour figure can be viewed at wileyonlinelibrary.com].

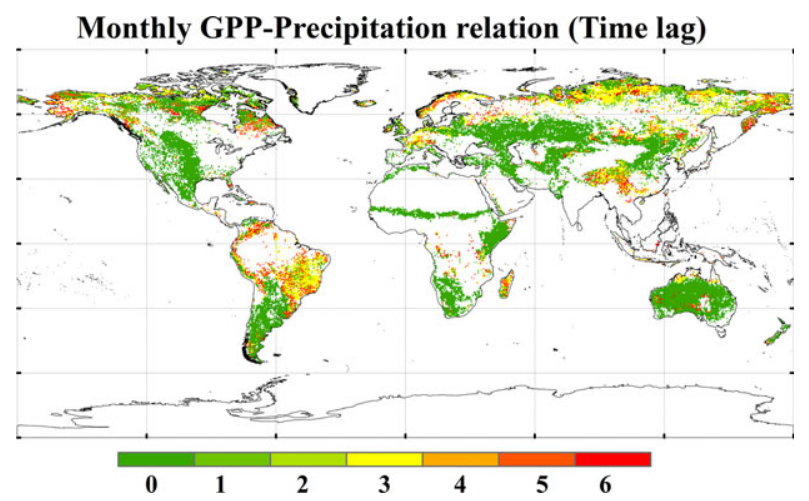

Fig. 12 Spatial distribution of time lag between precipitation and GPP. Positive numbers in lag indicate that precipitation precedes GPP. [Colour figure can be viewed at wileyonlinelibrary.com].

rapid. Similarly, precipitation changes will greatly influence carbon sequestration in these regions. As for polar/alpine climate zones, the maximum correlation coefficient was obtained when GPP preceded precipitation two months (Fig. 13d). Regarding temporal changes in the monthly GPP-precipitation relationship, all climate zones showed a relatively constant correlation coefficient for the past 30 years.

\section{Discussion}

\section{Comparison with other methods}

Generally, the spatial distribution of MTE-GRASS GPP is similar to JUNG11 (Fig. S3). However, this study tends to underestimate GPP than JUNG11 in regions with high latitudes or drier climate, particularly in central Australia and Saudi Arabia where JUNG11 predicts mean annual GPP of 100-300 $\mathrm{g} \mathrm{C} \mathrm{m}^{-2} \mathrm{yr}^{-1}$, while MTEGRASS has weaker GPP, typically below $50 \mathrm{~g} \mathrm{C} \mathrm{m}^{-2}$ $\mathrm{yr}^{-1}$ (Fig. S3a,b). This difference may result from grassland definition. Take Australia for an example, the majority of areas in MTE-GRASS were covered by grasses. In comparison, in JUNG11, besides grasslands, about $40 \%$ of the land cover was defined as shrubs (Jung et al., 2006), which generally has relatively higher productivity than grasslands. Then again, the proportion of grasslands in each pixel may also cause a discrepancy. This could be further proved as follows. By calculating the fraction of grasslands in each grid for land cover map used in both MTE-GRASS and JUNG11, we made a comparison when this fraction is above $0.7,0.8,0.85$, and 0.9 , respectively. It was shown that GPP from MTE-GRASS and JUNG11 tends to be more consistent with higher proportion of grasslands (Fig. S4). Another major reason may lie in the grassland management intensity. In regions with relatively higher intensity, for example, southwestern North America, Central Europe, and China's coastal regions, MTEGRASS usually produced lower GPP than that in JUNG11 (Figs S1 and S3c). Overall, measured GPP from eddy covariance flux agrees well with that from both MTE-GRASS and JUNG11 (Fig. S5), showing that MTE algorithm is feasible and able to reproduce the grasslands GPP. However, MTE-GRASS tends to have a relatively greater index of agreement (IOA) (Willmott et al., 1985), indicating that it is necessary to consider management intensity in estimating grasslands GPP.

Investigating changes in grassland GPP is of great significance to better understanding of global carbon cycle because this ecosystem is greatly sensitive to climate change and human activities (Scurlock \& Hall, 1998; Knapp \& Smith, 2001; Piao et al., 2007). At the global scale, process-driven models provide an important tool to estimate vegetation productivity. Nevertheless, in addition to suffering from numbers of parameters that are often not possible to obtain, most of these models failed to consider extreme climate and the vegetation productivity-climate feedbacks (Piao et al., 2014; Smith et al., 2015). Alternatively, data-driven models provide new insights into scientific research. With the promotion of the global scientific programs, it has accumulated abundant observation data, and scientific 
(a) Tropical

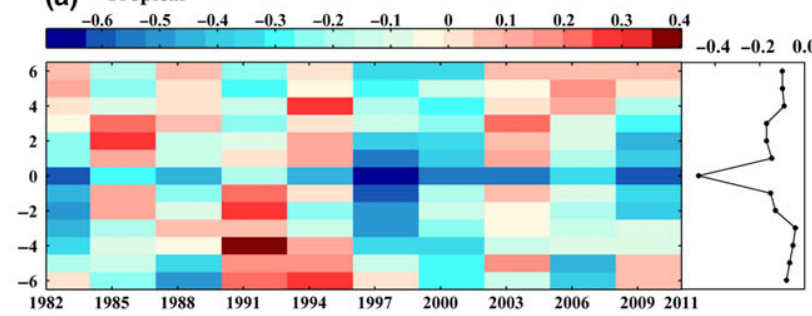

(c) Temperate
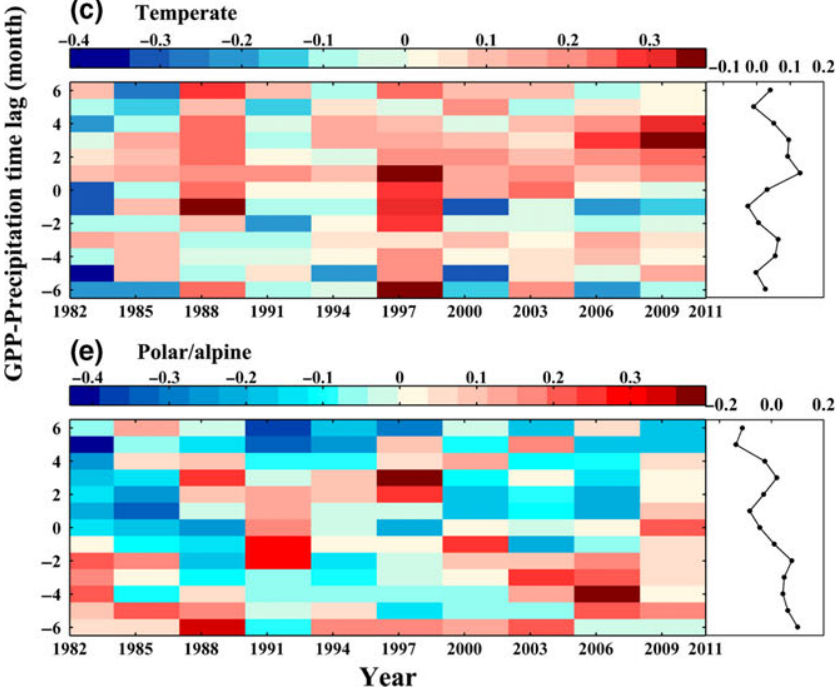

(b) Arid/semiarid

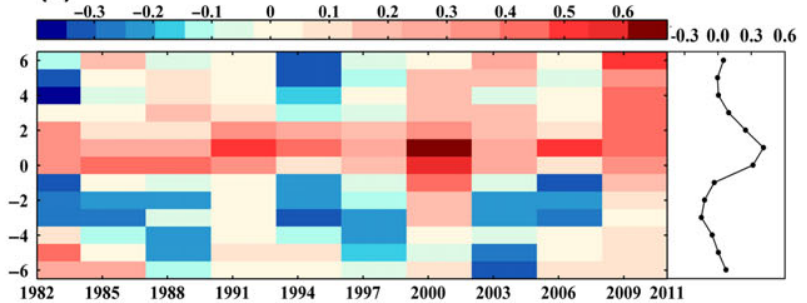

(d) Continental

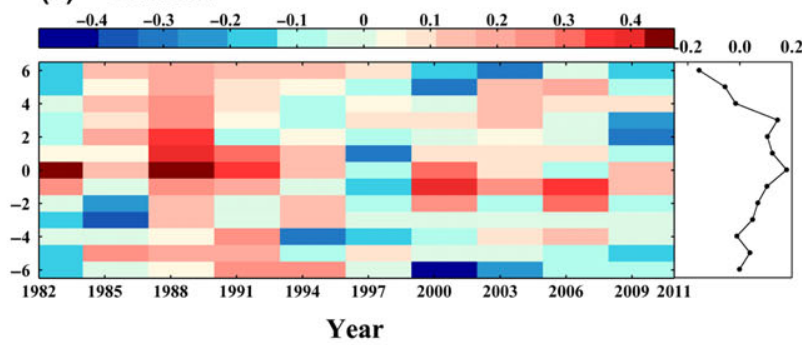

Fig. 13 Windowed cross-correlations between monthly GPP and precipitation anomalies over different climate zones. Positive numbers in lag indicate that precipitation precedes GPP. The inset on the right shows the average correlation coefficients of each lag. [Colour figure can be viewed at wileyonlinelibrary.com].

research has already entered an era of 'Big data'. Under this context, research methodology has been gradually changed from hypothesis-driven into data-driven. A report from National Research Council (2012) stated that high-accuracy and high-stability observation data are essential for better understanding of climate system behavior, extreme events formation mechanism, and long-term trend of climate change. Among several data-driven methods, MTE, which uses observed flux data as training sample, has an obvious advantage in mining data relations and provides a feasible and better way to capture the actual details of global grassland productivity.

\section{Distribution of grassland GPP}

At the global scale, the spatial gradient of vegetation productivity was primarily limited by suboptimum climatic conditions such as insufficient precipitation, lower temperature, and cloudiness (Nemani et al., 2003; Anav et al., 2015). Indeed, our results showed that lowproductivity grassland ecosystems mainly correspond to cold regions with negative mean annual temperature ranging from 0 to $-20{ }^{\circ} \mathrm{C}$, or arid/semiarid areas where the evaporative demand greatly exceeded the amount of annual precipitation as a result of high temperature (above $25^{\circ} \mathrm{C}$ ). By contrast, higher productivity (>1500 $\mathrm{g} \mathrm{C} \mathrm{m}^{-2} \mathrm{yr}^{-1}$ ) was generally found in tropics followed by humid temperate areas (Fig. 5) where the climatic condition is featured by sufficient precipitation $\left(>1200 \mathrm{~mm} \mathrm{yr}^{-1}\right.$ ), warm temperature (ranging between 20 and $30^{\circ} \mathrm{C}$ ), and moderate radiation (6000$7000 \mathrm{MJ} \mathrm{yr}^{-1}$ ).

Water resources is a dominant control on plant growth and production, and the availability of which influences more than half of the primary production of the world's terrestrial ecosystem (Heimann \& Reichstein, 2008). At the continental scale (North America), aboveground net primary production (ANPP) is detected strongly correlated with annual precipitation with a $R^{2}$ of 0.55 (Knapp \& Smith, 2001). Similarly, Nemani et al. (2003) showed that water availability most strongly limits vegetation productivity over $40 \%$ of the world vegetation. However, the relationship between precipitation and vegetation production was much stronger in grassland ecosystems. By regression 
annual GPP against annual precipitation across all climate zones, we found that $71 \%$ of the spatial variability in annual GPP can be explained by that in precipitation (Fig. S6), which was partially supported by work based on long-term data from the Inner Mongolia steppe region (Bai et al., 2008) and by analysis of 9500 sites data from the central United States (Sala et al., 1988), suggesting the overwhelming importance of water availability as a control on grassland productivity. This can be explained by the fact that about $62 \%$ of grasslands were distributed in arid/semiarid zones (Fig. 2), where moisture availability is commonly recognized as a primary resource limiting terrestrial biological activity (Huxman et al., 2004; Biederman et al., 2016).

\section{Changes in grassland GPP}

As stated earlier, terrestrial GPP of global grasslands increased at an annual rate of $0.023 \mathrm{Pg} \mathrm{C}^{-1}$ for the past 30 years, of which the trend is dominated by arid/ semiarid ecosystems $(54 \%)$, being consistent with a recent work by Ahlström et al. (2015). However, our study further found that this dominated role was also in all seasons (except for JJA), especially in summer of the SH (Fig. 8j). This situation is also exemplified by the vast inland regions of Australia, the driest inhabited continent. Many researches have pointed that Australia experienced an increase in greenness derived from satellite remote sensing over recent decades (Donohue et al., 2009; Fensholt et al., 2012). It could be explained that GPP had significant positive correlations with total precipitation, and a wet trend over the past three decades increased GPP in these regions (Figs 10 and S7a, e). Besides, altered precipitation frequency and intensity may also be responsible for the greening trend in arid/semiarid regions (Donohue et al., 2009).

In the last 30 years, global grasslands GPP does not show a monotonic trend, with two jumps in 1997 and 2010 (Fig. 7), a $4.4 \%$ and $5.9 \%$ increase compared to the 1982-2011 mean annual GPP, respectively. More than $61 \%(60 \%)$ of the grasslands worldwide experienced positive annual GPP anomalies in 1997 (2010). As shown in Fig. 14, almost the whole North America, most of China, eastern Siberia, and eastern Australia had a positive increase in GPP of more than 1.5 standard deviations, and even larger in 2010 (Fig. 14b). The positive anomaly of GPP over the high latitude in North America and eastern Siberia may be associated with the warming temperature (Fig. S8c,d). By contrast, the other areas with increased GPP could be ascribed to the increased precipitation (Fig. S8a,b). Further investigation suggests that about half of the global GPP anomalies could be explained by just arid/semiarid regions (Table S5). Seasonal GPP anomalies in 1997
(2010) over these regions ranged from $8.7 \%(15.5 \%)$ in MAM, $2.3 \%(11.1 \%)$ in JJA, and $17.1 \%(17.1 \%)$ in SON to $24.7 \%(22.4 \%)$ in DJF, with almost all anomalies being prominent extremes compared with a $2.6-6.8 \%$ (5.6-11.7\%) interannual variability over the past 30 years. Obviously, 38\% (43\%) of the pixel in the arid/ semiarid ecosystems experienced positive annual GPP anomalies in 1997 (2010) of more than 3 standard deviations. These large positive grassland GPP anomalies in these regions in 2010, especially in Australia, can be attributed to an expected consequence of the response of drought-adapted vegetation to a strong rainfall pulse in the preceding year (Haverd et al., 2016), which is related to La Niña events characterized by intense and abundant rainfall. For example, northeastern Australia 2010/2011 rainfall was $84 \%$ above average in response to 2010/2011 La Niña events (Ummenhofer et al., 2015).

In addition, our analysis showed that global GPP IAV is largely driven by arid/semiarid ecosystem which is very sensitive to precipitation variations (Figs 8 and 11a). These findings partly support the results of previous study by Ahlström et al. (2015), who found that the GPP anomalies of semiarid ecosystems alone contribute to $39 \%$ in LPJ-GUESS and a median of $65 \%$ in the TRENDY model ensemble to global NBP (net biome production) IAV. Likewise, a recent study found that the global carbon sink anomaly of 2011 was driven by growth of semiarid vegetation in the Southern Hemisphere (Poulter et al., 2014). Compared with the previous research, our study further revealed that arid/semiarid ecosystems dominated the variability of the GPP for all seasons, suggesting that this ecosystem has becoming an important driver of global carbon cycle interannual variation. Such a dominated role may result from the fact that variability of temperature and SWrad is generally far lower than that of precipitation at the annual scale (Fig. S9); therefore, temperature-controlled and SWrad-controlled GPP variability regions have lower GPP IAV (Fig. 8a,f). On the other hand, most of these regions either have high biological activity with small areas or have high biological activity with large areas but with low productivity (tundra ecosystem). By contrast, in the arid/semiarid regions that are dominated by precipitation, GPP has larger variability due to the larger variation in precipitation.

Although evidences from both flux tower and field experiment have shown that precipitation is the dominant climatic driver of global grassland ecosystems (Merbold et al., 2009; Cherwin \& Knapp, 2012), our study highlights that temperature and radiation together shared half of the world grassland GPP variability (Fig. 9d). However, compared with precipitation, the impact of temperature on vegetation has been mixed with positive effect, negative effect, and little 


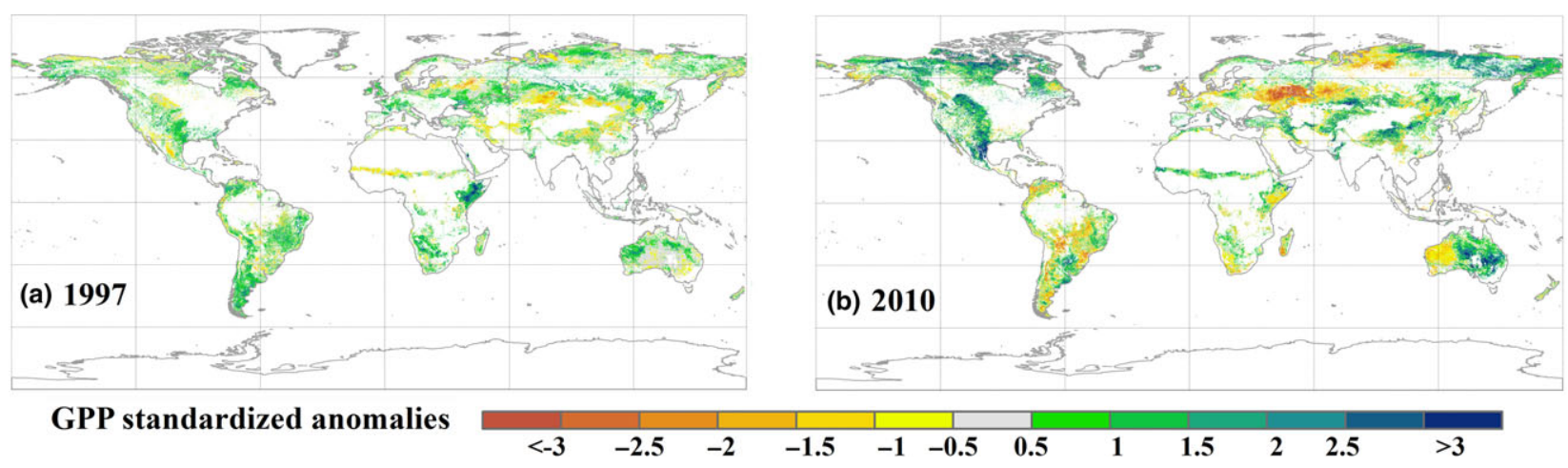

Fig. 14 Spatial distributions of standardized anomalies (anomalies/standard deviation) of grassland GPP in (a) 1997 and (b) 2010 . The anomalies are with respect to the period of 1982-2011 long-term annual average. [Colour figure can be viewed at wileyonlinelibrary.com].

effect depending on geographical position (Piao et al., 2008; Fay et al., 2011). For example, summer warming might be favorable for vegetation growth in arctic regions (Figs $6 \mathrm{c}, 9 \mathrm{~d}$ and S7 h), while negative in temperate and arid/semiarid areas where soil moisture limitations prevail (Ciais et al., 2005; Wolf et al., 2016), owing to higher atmospheric water demand (i.e., higher potential evapotranspiration), which requires more soil water to support vegetation growth. The pattern of trend in GPP during JJA presents high spatial heterogeneity, particularly in the $\mathrm{NH}$, with the largest decreasing trends in eastern Europe and Central Asia (Fig. 6c). This decline in GPP can be ascribed to the increased water stress from increased temperature and decreased precipitation (Figs S7c and 7h), which is partly in line with previous studies in which current decrease in vegetation productivity observed across the $\mathrm{NH}$ is due to recent hotter and drier summer climate (Angert et al., 2005; Park \& Sohn, 2010).

The interannual variability of vegetation productivity may be caused by both climate change and ecosystem responses (Zhang et al., 2016). Ecosystem adaptation to altered climatic availability may change the sensitivity of vegetation productivity to temporal variation in climate change (Biederman et al., 2016). For example,

Marcolla et al. (2011) determined that alpine mea-

dow has the ability to acclimatize and to limit the

IAV of carbon fluxes induced by climate variability. Likely, Piao et al. (2014) reported that the relationship between interannual variability of northern vegetation activity and temperature greatly declined over the recent 30 years. However, our result shows that, at the monthly scale, all regions have a relatively unchanged relationship between GPP and precipitation during the study period (Fig. 13), indicating that the impact of water availability on grassland GPP is almost constant throughout the 30 years. Moreover, the maximum correlation coefficient was found when GPP preceded precipitation two months in polar/alpine climate zones
(Fig. 13e). These regions are featured by cold climate; average annual temperature is below $-15{ }^{\circ} \mathrm{C}$ (Fig. S2), and thus, temperature dominated the variation in GPP. The current year precipitation (July to September) will be quickly frozen and could not be used for vegetation growth. Once temperature exceeds zero ${ }^{\circ} \mathrm{C}$ (around July), the frozen water starts to thaw and therefore provides water for vegetation use in the next year.

\section{Implications for carbon cycle}

The concentration of global atmospheric $\mathrm{CO}_{2}$ has increased by nearly $100 \mathrm{ppm}$ over the last 150 years, an increase of $\sim 35 \%$ above the preindustry (Raupach et al., 2007). Only less than half of the anthropogenic $\mathrm{CO}_{2}$ emissions remained in the atmosphere, while the rest was absorbed by the oceans (29\%) and terrestrial (26\%) biosphere (Le Quere et al., 2009). The growth rate of atmospheric $\mathrm{CO}_{2}$ was found to be paused since the start of the twenty-first century, which is primarily associated with increases in the terrestrial sink induced by the combined effect of $\mathrm{CO}_{2}$ fertilization effect and the retarded rate of warming on global respiration (Keenan et al., 2016). As a critical component of the terrestrial ecosystem, grassland ecosystems play an important role in regulating the terrestrial carbon cycle and the climate system. Grassland GPP from MTE-GRASS has increased over the past several decades, implying that this ecosystem has become important sinks for atmospheric $\mathrm{CO}_{2}$ to some extent. In comparison with the global terrestrial ecosystem average, our estimated GPP increasing trend is much higher $(0.2 \%$ vs. $0.07 \%)$, suggesting that grassland has been playing an ever-increasing role in global carbon sequestration.

Another important finding of this study is that the trend of global GPP was dominated by arid/semiarid regions, which are often considered to be fragile and sensitive to strong interactions between human activities and climate changes (Kaptué et al., 2015). The 
desertification of global drylands mainly came from livestock (Mabbutt, 1984), while some other studies concluded that drought rather than grazing is responsible for the land degradation of the Sahara (Nicholson et al., 2010). Anyhow, in some sense, the increase in productivity of these dry regions can enhance livestock carrying capacities, and thus, it can greatly strengthen the social system stability. However, the variability of global grassland GPP was mainly controlled by arid/ semiarid regions, implying a high susceptibility of grassland ecosystems productivity to projected changes in precipitation over the twenty-first century (Intergovernmental Panel on Climate Change, 2007, 2013).

\section{Uncertainties of GPP estimation}

To our best knowledge, in current MTE models, the information of management activities was only reflected by satellite greenness data (e.g., normalized difference vegetation index (NDVI)), which may not exactly simulate the actual grassland productivity. To that end, we trained a new model, MTE-GRASS, with two critical grassland management practices being considered. This model performs well with observed GPP, especially in temperate and continental regions (Fig. $4 \mathrm{~b}, \mathrm{c})$. However, it is worthwhile to further analyze the uncertainties in MTE-GRASS GPP. A core limitation in the MTE method is that it has a low capacity in extrapolating to completely different environmental conditions, and depends on the availability of sufficient data (Beer et al., 2010). Therefore, additional data especially in Australia, Africa, and tundra regions should be further collected and produce more robust map for global grassland GPP in the future. On the other hand, site-specific information such as soil properties, topography, nutrient availability, and grass species is not taken into consideration in the MTE-GRASS, which reduces its ability to capture the actual details of the spatial distribution of grassland productivity (Chang et al., 2015b). In addition, as discussed by Jung et al. (2009) and Piao et al. (2013), variables that reflect the trends in climate, rather than mean climate, could be considered as additional predictors in the future.

Another important limitation in the MTE-GRASS may be that this model assumes $\mathrm{CO}_{2}$ level constant. $\mathrm{CO}_{2}$ is a primary substrate for photosynthesis for all terrestrial higher plants, and the increased atmospheric $\mathrm{CO}_{2}$ concentration has been verified as having a fertilization effect on photosynthesis (Donohue et al., 2013; Yang et al., 2016b) and influences the GPP estimation to some extent. It was reported that global emission of $\mathrm{CO}_{2}$ from fossil fuel combustion and cement production has continued to grow by $2.5 \%$ per year on average over the past decade, and will exceed $700 \mathrm{~mol} \mathrm{~mol}^{-1}$ by 2100 (Watson et al., 1990; Friedlingstein et al., 2014). Although this $\mathrm{CO}_{2}$ fertilization effect can be partly reflected through remotely sensed $f_{\mathrm{PAR}}$, the underlying mechanism may be complex given the interactions between climate, vegetation, and soil moisture conditions (Donohue et al., 2013). Therefore, $\mathrm{CO}_{2}$ fertilization effect should be included in future training.

Uncertainties also come from the grassland map. With regard to the economy and public awareness development, grassland area may increase from large-scale ecological restoration (e.g., The Grain-for-Green project in China). However, because we do not have access to grassland maps of equal quality and accuracy for the entire study period, it is assumed that the distribution of grassland is constant in our study, which may be another type of uncertainties in the estimation of GPP.

\section{Acknowledgments}

This work was funded by Key Research and Development Program of China (2016YFC0501601), National Natural Science Foundation of China $(41571130083,41390464)$, National Special Program on Basic Science and Technology Research of China (2014FY210100), and Fundamental Research Funds for the Central Universities (GK201603072). We greatly thank Jinfeng Chang, Martin Jung, and Zaichun Zhu, who provided data on grassland management intensity, GPP, and $f_{\text {PAR }}$ data, respectively. We also thank Shushi Peng for helpful discussion on the manuscript. Thanks are also given to three anonymous reviewers and editor for their constructive comments. The authors declare no conflict of interest.

\section{References}

Ahlström A, Raupach MR, Schurgers G et al. (2015) The dominant role of semiarid ecosystems in the trend and variability of the land CO2 sink. Science, 348, 895-899.

Anav A, Friedlingstein P, Beer C et al. (2015) Spatiotemporal patterns of terrestrial gross primary production: a review. Reviews of Geophysics, 53, 2015 RG000483.

Angert A, Biraud S, Bonfils C, et al. (2005) Drier summers cancel out the $\mathrm{CO}_{2}$ uptake enhancement induced by warmer springs. Proceedings of the National Academy of Sciences of the United States of America, 102, 10823-10827.

Bai Y, Wu J, Xing Q, Pan Q, Huang J, Yang D, Han X (2008) Primary production and rain use efficiency across a precipitation gradient on the Mongolia plateau. Ecology, 89, 2140-2153.

Battin TJ, Luyssaert S, Kaplan LA, Aufdenkampe AK, Richter A, Tranvik LJ (2009) The boundless carbon cycle. Nature Geoscience, 2, 598-600.

Beer C, Reichstein M, Tomelleri E et al. (2010) Terrestrial gross carbon dioxide uptake: global distribution and covariation with climate. Science, 329, 834-838.

Biederman JA, Scott RL, Goulden ML et al. (2016) Terrestrial carbon balance in a drier world: the effects of water availability in southwestern North America. Global Change Biology, 22, 1867-1879.

Boker SM, Rotondo JL, Xu M, King K (2002) Windowed cross-correlation and peak picking for the analysis of variability in the association between behavioral time series. Psychological Methods, 7, 338-355.

Chang JF, Viovy N, Vuichard N et al. (2013) Incorporating grassland management in ORCHIDEE: model description and evaluation at 11 eddy-covariance sites in Europe. Geoscientific Model Development, 6, 2165-2181.

Chang JF, Ciais P, Viovy N, Vuichard N, Sultan B, Soussana JF (2015a) The greenhouse gas balance of European grasslands. Global Change Biology, 21, 3748-3761.

Chang JF, Viovy N, Vuichard N et al. (2015b) Modeled Changes in Potential Grassland Productivity and in Grass-Fed Ruminant Livestock Density in Europe over 1961-2010. PLoS ONE, 10, e0127554. 
Chang JF, Ciais P, Viovy N et al. (2016) Effect of climate change, CO2 trends, nitrogen addition, and land-cover and management intensity changes on the carbon balance of European grasslands. Global Change Biology, 22, 338-350.

Chen T, RaM DJ, Liu YY, Van Der Werf GR, Dolman AJ (2014) Using satellite based soil moisture to quantify the water driven variability in NDVI: A case study over mainland Australia. Remote Sensing of Environment, 140, 330-338.

Cherwin K, Knapp A (2012) Unexpected patterns of sensitivity to drought in three semi-arid grasslands. Oecologia, 169, 845-852.

Chou WW, Silver WL, Jackson RD, Thompson AW, Allen-Diaz B (2008) The sensitivity of annual grassland carbon cycling to the quantity and timing of rainfall. Global Change Biology, 14, 1382-1394.

Christian B, Joshi N, Saini M et al. (2015) Seasonal variations in phenology and productivity of a tropical dry deciduous forest from MODIS and Hyperion. Agricultural and Forest Meteorology, 214-215, 91-105.

Ciais P, Reichstein M, Viovy N et al. (2005) Europe-wide reduction in primary productivity caused by the heat and drought in 2003. Nature, 437, 529-533.

Donat MG, Lowry AL, Alexander LV, O'gorman PA, Maher N (2016) More extreme precipitation in the world's dry and wet regions. Nature Climate Change, 6. doi: 10 1038/nclimate2941.

Donohue RJ, Mcvicar TR, Roderick ML (2009) Climate-related trends in Australian vegetation cover as inferred from satellite observations, 1981-2006. Global Change Biology, 15, 1025-1039.

Donohue RJ, Roderick ML, Mcvicar TR, Farquhar GD (2013) Impact of CO2 fertilization on maximum foliage cover across the globe's warm, arid environments. Geophysical Research Letters, 40, 3031-3035.

Fay PA, Blair JM, Smith MD, Nippert JB (2011) Relative effects of precipitation variability and warming on grassland ecosystem function. Biogeosciences Discussions, 8 3053-3068.

Fensholt R, Langanke T, Rasmussen K et al. (2012) Greenness in semi-arid areas across the globe 1981-2007 - an Earth Observing Satellite based analysis of trends and drivers. Remote Sensing of Environment, 121, 144-158.

Friedlingstein P, Andrew RM, Rogelj J et al. (2014) Persistent growth of CO2 emissions and implications for reaching climate targets. Nature Geoscience, 7, 709-715.

Fry EL, Manning P, Allen DGP et al. (2013) Plant functional group composition modifies the effects of precipitation change on grassland ecosystem function. PLoS ONE, 8, e57027.

Fu X, Tang C, Zhang X, Fu J, Jiang D (2014) An improved indicator of simulated grassland production based on MODIS NDVI and GPP data: a case study in the Sichuan province, China. Ecological Indicators, 40, 102-108

Gilmanov TG, Soussana JF, Aires L et al. (2007) Partitioning European grassland net ecosystem $\mathrm{CO} 2$ exchange into gross primary productivity and ecosystem respiration using light response function analysis. Agriculture, Ecosystems \& Environment, 121, 93-120.

Goetz S, Prince SD (1999) Modelling terrestrial carbon exchange and storage: evidence and implications of functional convergence in light-use efficiency. Advances in Ecological Research, 28, 57-92.

Gök M, Coupé VMH, Berkhof J et al. (2000) Respiration as the main determinant of carbon balance in European forests. Nature, 404, 861-865.

Goulden ML, McMillan AMS, Winston GC, Rocha AV, Manies KL, Harden JW, Bond-Lamberty BP (2010) Patterns of NPP, GPP, respiration, and NEP during boreal forest succession. Global Change Biology, 17, 855-871.

Guo Q, Hu Z, Li S et al. (2015) Contrasting responses of gross primary productivity to precipitation events in a water-limited and a temperature-limited grassland ecosystem. Agricultural and Forest Meteorology, 214, 169-177.

Haverd V, Smith B, Trudinger C (2016) Dryland vegetation response to wet episode, not inherent shift in sensitivity to rainfall, behind Australia's role in 2011 global carbon sink anomaly. Global Change Biology, 22, 2315-2316.

Heimann M, Reichstein M (2008) Terrestrial ecosystem carbon dynamics and climate feedbacks. Nature, 451, 289-292.

Herrero M, Havlík P, Valin H et al. (2013) Biomass use, production, feed efficiencies, and greenhouse gas emissions from global livestock systems. Proceedings of the National Academy of Sciences of the United States of America, 110, 20888-20893.

Huxman TE, Smith MD, Fay PA et al. (2004) Convergence across biomes to a common rain-use efficiency. Nature, 429, 651-654.

IPCC (2013) Climate change 2013: the physical science basis. In: Contribution of Working Group I to the Fifth Assessment Report of the Intergovernmental Panel on Climate Change (eds Stocker TF et al.), Cambridge University Press, Cambridge.

IPCC (2007) Intergovernmental Panel on Climate Change: The Physical Science Basis. In: Contribution of Working Group I to the Fourth Assessment Report of the Intergovernmental Panel on Climate Change (eds Solomon S, Qin D, Manning M et al.) Cambridge Univ. Press, Cambridge, UK.
Jung M, Henkel K, Herold M, Churkina G (2006) Exploiting synergies of global land cover products for carbon cycle modeling. Remote Sensing of Environment, 101, 534 553.

Jung M, Reichstein M, Bondeau A (2009) Towards global empirical upscaling of FLUXNET eddy covariance observations: validation of a model tree ensemble approach using a biosphere model. Biogeosciences, 6, 2001-2013.

Jung M, Reichstein M, Margolis HA et al. (2011) Global patterns of land-atmosphere fluxes of carbon dioxide, latent heat, and sensible heat derived from eddy covariance, satellite, and meteorological observations. Journal of Geophysical Research: Biogeosciences, 116, G00J07.

Kanamitsu M, Ebisuzaki W, Woollen J, Yang S-K, Hnilo J, Fiorino M, Potter G (2002) Ncep-doe amip-ii reanalysis (r-2). Bulletin of the American Meteorological Society, 83 1631-1643.

Kaptue AT, Prihodko L, Hanan NP (2015) On regreening and degradation in Sahelian watersheds. Proceedings of the National Academy of Sciences of the United States of America, 112, 12133-12138.

Keenan TF, Prentice IC, Canadell JG, Williams CA, Wang H, Raupach M, Collatz G] (2016) Recent pause in the growth rate of atmospheric $\mathrm{CO}_{2}$ due to enhanced terrestrial carbon uptake. Nature Communications, 7, 13428.

Knapp AK, Smith MD (2001) Variation among biomes in temporal dynamics of aboveground primary production. Science, 291, 481-484.

Kottek M, Grieser J, Beck C, Rudolf B, Rubel F (2006) World map of the Köppen-Geiger climate classification updated. Meteorologische Zeitschrift, 15, 259-263.

Kruska RL, Reid RS, Thornton PK, Henninger N, Kristjanson PM (2003) Mapping livestock-oriented agricultural production systems for the developing world. Agricultural Systems, 77, 39-63.

Le Quere C, Raupach MR, Canadell JG, Marland G et al. (2009) Trends in the sources and sinks of carbon dioxide. Nature Geoscience, 2, 831-836.

Li Z, Yu G, Xiao X et al. (2007) Modeling gross primary production of alpine ecosystems in the Tibetan Plateau using MODIS images and climate data. Remote Sensing of Environment, 107, 510-519.

Liang W, Yang Y, Fan D et al. (2015) Analysis of spatial and temporal patterns of net primary production and their climate controls in China from 1982 to 2010. Agricultural and Forest Meteorology, 204, 22-36.

Mabbutt JA (1984) A New Global Assessment of the Status and Trends of Desertification. Environmental Conservation, 11, 103-113.

Macbean N, Maignan F, Peylin P, Bacour C, Bréon F-M, Ciais P (2015) Using satellite data to improve the leaf phenology of a global terrestrial biosphere model. Biogeosciences, 12, 7185-7208.

Marcolla B, Cescatti A, Manca G et al. (2011) Climatic controls and ecosystem responses drive the inter-annual variability of the net ecosystem exchange of an alpine meadow. Agricultural \& Forest Meteorology, 151, 1233-1243.

Mcknight TL, Hess D (2000) Climate Zones and Types: The Köppen System. Physical Geography: A Landscape Appreciation, pp. 235-237. Prentice Hall, Upper Saddle River, NJ.

Merbold L, Ardö J, Arneth A et al. (2009) Precipitation as driver of carbon fluxes in 11 African ecosystems. Biogeosciences, 6, 1027-1041.

Mitchell TD, Jones PD (2005) An improved method of constructing a database of monthly climate observations and associated high-resolution grids. International Journal of Climatology, 25, 693-712.

Monteith J (1972) Solar radiation and productivity in tropical ecosystems. Journal of Applied Ecology, 9, 747-766.

Monteith JL, Moss C (1977) Climate and the efficiency of crop production in Britain [and discussion]. Philosophical Transactions of the Royal Society B: Biological Sciences, 281, 277-294.

Mowll W, Blumenthal DM, Cherwin K et al. (2015) Climatic controls of aboveground net primary production in semi-arid grasslands along a latitudinal gradient portend low sensitivity to warming. Oecologia, 177, 959-969.

Murray-Tortarolo G, Friedlingstein P, Sitch S et al. (2016) The carbon cycle in Mexico: past, present and future of $\mathrm{C}$ stocks and fluxes. Biogeosciences, 13, 223-238

National Research Council (2012) Education for Life and Work: Developing Transferable Knowledge and Skills in the 21st Century. The National Academies Press, Washington, DC.

Nemani RR, Keeling CD, Hashimoto $\mathrm{H}$ et al. (2003) Climate-driven increases in global terrestrial net primary production from 1982 to 1999. Science, 300, 1560-1563.

Nicholson SE, Tucker CJ, Ba MB (2010) Desertification, Drought, and Surface Vegetation: An Example from the West African Sahel. Bulletin of the American Meteorological Society, 79, 815-829.

Novick KA, Stoy PC, Katul GG, Ellsworth DS, Siqueira MBS, Juang J, Oren R (2004) Carbon dioxide and water vapor exchange in a warm temperate grassland. Oecologia, 138, 259-274. 
Park HS, Sohn BJ (2010) Recent trends in changes of vegetation over East Asia coupled with temperature and rainfall variations. Journal of Geophysical Research, 115, D14101.

Piao S, Fang J, Zhou L, Tan K, Tao S (2007) Changes in biomass carbon stocks in China's grasslands between 1982 and 1999. Global Biogeochemical Cycles, 21, B2002 (2001-2010).

Piao S, Ciais P, Friedlingstein P et al. (2008) Net carbon dioxide losses of northern ecosystems in response to autumn warming. Nature, 451, 49-52.

Piao S, Sitch S, Ciais P et al. (2013) Evaluation of terrestrial carbon cycle models for their response to climate variability and to CO2 trends. Global Change Biology, 19, 2117-2132.

Piao S, Nan H, Huntingford C et al. (2014) Evidence for a weakening relationship between interannual temperature variability and northern vegetation activity. Nature Communications, 5, 5018-5018.

Ponce-Campos GE, Moran MS, Huete A et al. (2013) Ecosystem resilience despite large-scale altered hydroclimatic conditions. Nature, 494, 349-352.

Poulter B, Frank D, Ciais P et al. (2014) Contribution of semi-arid ecosystems to interannual variability of the global carbon cycle. Nature, 509, 600-603.

Raupach MR, Marland G, Ciais P, Le Que're' C, Canadell JG, Klepper G, Field $\mathrm{CB}$ (2007) Global and regional drivers of accelerating $\mathrm{CO}_{2}$ emissions. Proceedings of the National Academy of Sciences of the United States of America, 104, 10288-10293.

Running SW, Nemani RR, Heinsch FA, Zhao M, Reeves M, Hashimoto H (2004) A continuous satellite-derived measure of global terrestrial primary production. BioScience, 54, 547-560.

Sala OE, Parton WJ, Joyce LA, Lauenroth WK (1988) Primary production of the central grassland region of the United States. Ecology, 69, 40-45.

Scurlock J, Hall D (1998) The global carbon sink: a grassland perspective. Global Change Biology, 4, 229-233.

Smith WK, Reed SC, Cleveland CC et al. (2015) Large divergence of satellite and Earth system model estimates of global terrestrial $\mathrm{CO} 2$ fertilization. Nature Climate Change, 6, 306-310.

Soussana J, Allard V, Pilegaard K et al. (2007) Full accounting of the greenhouse gas (CO2, N2O, CH4) budget of nine European grassland sites. Agriculture, Ecosystems E Environment, 121, 121-134.

Suttie JM, Reynolds SG, Batello C (2005) Grasslands of the World. Food and Agriculture Organization of the United Nations, Rome, Italy.

Ummenhofer CC, Sen Gupta A, England MH, Taschetto AS, Briggs PR, Raupach MR (2015) How did ocean warming affect Australian rainfall extremes during the 2010/2011 La Niña event? Geophysical Research Letters, 42, 9942-9951.

Vens C, Blockeel H (2006) A simple regression based heuristic for learning model trees. Intelligent Data Analysis, 10, 215-236.

Wang Y, Witten IH (1997) Inducing Model Trees for Continuous Classes. Proc.of European Conf.on Machine Learning Poster Papers, 128-137.

Watson R, Rodhe H, Oeschger H, Siegenthaler U (1990) Greenhouse gases and aerosols. Climate Change: the IPCC scientific assessment, 1, 17
Willmott CJ, Ackleson SG, Davis RE et al. (1985) Statistics for the evaluation and comparison of models. Journal of Geophysical Research Atmospheres, 90, 8995-9005.

Wohlfahrt G, Hammerle A, Haslwanter A, Bahn M, Tappeiner U, Cernusca A (2008) Seasonal and inter-annual variability of the net ecosystem $\mathrm{CO} 2$ exchange of a temperate mountain grassland: Effects of weather and management. Journal of Geophysical Research: Atmospheres, 113, 693-702.

Wolf S, Keenan TF, Fisher JB et al. (2016) Warm spring reduced carbon cycle impact of the 2012 US summer drought. Proceedings of the National Academy of Sciences of the United States of America, 113, 5880-5885.

Wu C, Niu Z, Tang Q, Huang W, Rivard B, Feng J (2009) Remote estimation of gross primary production in wheat using chlorophyll-related vegetation indices. Agricultural and Forest Meteorology, 149, 1015-1021.

Yang YT, Shang SH, Guan HD, Jiang L (2013) A novel algorithm to assess gross primary production for terrestrial ecosystems from MODIS imagery. Journal of Geophysical Research: Biogeosciences, 118, 590-605.

Yang YT, Guan HD, Shang SH, Long D, Simmons CT (2014a) Towards the use of the MODIS ET product to estimate terrestrial GPP for non-forest ecosystems. IEEE Geoscience and Remote Sensing Letters, 11, 1624-1628.

Yang YT, Long D, Guan H, Scanlon BR, Simmons CT, Jiang L, Xu X (2014b) GRACE satellite observed hydrological controls on interannual and seasonal variability in surface greenness over mainland Australia. Journal of Geophysical Research: Biogeosciences, 119, 2245-2260.

Yang YT, Donohue RJ, Mcvicar TR, Roderick ML (2015) An analytical model for relating global terrestrial carbon assimilation with climate and surface conditions using a rate limitation framework. Geophysical Research Letters, 42, 9825-9835.

Yang YT, Guan H, Batelaan O et al. (2016a) Contrasting responses of water use efficiency to drought across global terrestrial ecosystems. Scientific Reports, 6. doi: 10. 1038/srep23284.

Yang YT, Donohue RJ, McVicar TR, Roderick ML, Hylke B (2016b) Long-term CO2 fertilization increases vegetation productivity and has little effect on hydrological partitioning in tropical rainforests. Journal of Geophysical Research: Biogeosciences, 121, 2125-2140.

Zeng Z, Wang T, Zhou F, Ciais P, Mao J, Shi X, Piao S (2014) A worldwide analysis of spatiotemporal changes in water balance-based evapotranspiration from 1982 to 2009. Journal of Geophysical Research: Atmospheres, 119, 2013JD020941.

Zhang T, Zhang Y, Xu M et al. (2016) Ecosystem response more than climate variability drives the inter-annual variability of carbon fluxes in three Chinese grasslands. Agricultural and Forest Meteorology, 225, 48-56.

Zhao M, Running SW (2010) Drought-Induced Reduction in Global Terrestrial Net Primary Production from 2000 Through 2009. Science, 329, 940-943.

Zhu Z, Bi J, Pan Y et al. (2013) Global data sets of vegetation leaf area index (LAI) $3 \mathrm{~g}$ and fraction of photosynthetically active radiation (FPAR) $3 \mathrm{~g}$ derived from global inventory modeling and mapping studies (GIMMS) normalized difference vegetation index (NDVI3 g) for the period 1981 to 2011. Remote Sensing, 5, 927. 


\section{Supporting Information}

Additional Supporting Information may be found in the online version of this article:

Data S1 Statistical Analysis Methods.

Table S1. Five climate zones according to Köppen-Geiger climate classification.

Table S2. Descriptions of 45 grassland sites trained in this study, including site number (No.), site ID, country, latitude (Lat), longitude (Lon), elevation (m), climate zone (Köppen-Geiger climate classification), and management intensity. Climate zone 1-4 represent tropical, arid/semiarid, temperate and continental climate, respectively.

Table S3. Descriptions of the flux sites validated in this study, including site number (No.), site ID, climate zone (Köppen-Geiger climate classification), slope of regression (a), linear regression intercept (b), modeling efficiency (NSE), determine coefficient of determination $\left(R^{2}\right)$, root mean square error (RMSE) and the bias (defined as modeled mean minus observed mean). Climate zone 24 represent arid/semiarid, temperate and continental climate, respectively.

Table S4. Statistic summary of the percentages of pixels showing trends in annual and seasonal GPP. Significant level is $95 \%$.

Table S5. GPP anomalies (Pg C $\mathrm{yr}^{-1}$ ) for each climate zone. The annual GPP anomalies for 1997 and 2010 are calculated relative to the period 1982-2011. GPP anomalies in the arid/semiarid regions are provided in bold text.

Figure S1. Spatial distribution of global grassland management intensity (1982-2011).

Figure S2. Spatial distributions of annual and seasonal (a-e) precipitation, (f-j) temperature and (k-o) short wave radiation (SWrad) for grasslands.

Figure S3. Spatial distribution of (a): MTE-GRASS GPP, (b) JUNG11 GPP, and (c) relative discrepancy between them expressed as (MTE-GRASS-JUNG11)/JUNG11 (\%) during the period 1982-2011.

Figure S4. Comparison between MTE-GRASS and JUNG11 monthly GPP of grasslands. Each point represents averaged GPP during the period 1982-2011. 0.9, 0.85, 0.8 and 0.7 refer to the fractions of global grasslands of each grid, respectively $\left(0.5^{\circ}\right.$ spatial resolution).

Figure S5. Index of agreement (IOA) for GPP between observation and simulation by JUNG11 and MTE-GRASS at 33 grassland sites. IOA varies from 0.0 to 1.0, with higher values indicating better model-data agreement.

Figure S6. Relationship between average annual precipitation and average annual GPP for global grasslands.

Figure S7. Spatial distributions of annual and seasonal trends in (a-e) precipitation, (f-j) temperature, and (k-o) SWrad during the period 1982-2011.

Figure S8. Spatial distributions of anomalies of (a and b) precipitation, (c and d) temperature, and (e and f) SWrad in 1997 and 2010. Figure S9. Spatial distributions of the coefficient of variation (CV) in (a) precipitation, (b) temperature, and (c) SWrad of the global grasslands. 